UNIVERSIDADE ESTADUAL PAULISTA “JÚLIO DE MESQUITA FILHO” FACULDADE DE CIÊNCIAS AGRONÔMICAS CÂMPUS DE BOTUCATU

\begin{abstract}
A COMUNIDADE DE BORBOLETAS FRUGÍVORAS DE ÁREAS EM PROCESSO DE RESTAURAÇÃO, FRAGMENTOS DE FLORESTA ESTACIONAL SEMIDECIDUAL E PASTAGENS.
\end{abstract}

PAULA RACHEL ROTTA FURLANETTI

Dissertação apresentada à Faculdade de Ciências Agronômicas da UNESP Campus de Botucatu, para obtenção do título de Mestre em Ciência Florestal.

BOTUCATU - SP

Março/2010 
UNIVERSIDADE ESTADUAL PAULISTA “JÚLIO DE MESQUITA FILHO” FACULDADE DE CIÊNCIAS AGRONÔMICAS CÂMPUS DE BOTUCATU

\title{
A COMUNIDADE DE BORBOLETAS FRUGÍVORAS DE ÁREAS EM PROCESSO DE RESTAURAÇÃO, FRAGMENTOS DE FLORESTA ESTACIONAL SEMIDECIDUAL E PASTAGENS.
}

PAULA RACHEL ROTTA FURLANETTI

\author{
Orientador: Vera Lex Engel \\ Co-orientador: Marcio Uehara-Prado
}

Dissertação apresentada à Faculdade de Ciências Agronômicas da UNESP Campus de Botucatu, para obtenção do título de Mestre em Ciência Florestal. 
FICHA CATALOGRÁFICA ELABORADA PELA SEÇÃO TÉCNICA DE AQUISIÇÃO E TRATAMENTO DA INFORMAÇÃ̃ - SERVIÇO TÉCNICO DE BIBLIOTECA E DOCUMENTAÇẨO UNESP - FCA LAGEADO - BOTUCATU (SP)

Furlanetti, Paula Rachel Rotta, 1981-

F985a A comunidade de borboletas frugivoras de áreas em processo de restauração, fragmentos de floresta estacional semidecidual e pastagens / Paula Rachel Rotta Furlanetti. - Botucatu, [s.n.], 2010.

vi, 61 f. : il., color., grafs., tabs.

Dissertação (Mestrado) - Universidade Estadual Paulista, Faculdade de Ciências Agronômicas, Botucatu, 2010

Orientador: Vera Lex Engel

Co-orientador: Marcio Uehara-Prado

Inclui bibliografia

1. Restauração ecológica. 2.Borboletas frugívoras. 3. Indicadores de restauração. 4. Nymphalidae. 5. Floresta estacional semidecidual. I. Engel, Vera Lex. II. Uehara-Prado, Marcio. III. Universidade Estadual Paulista"Júlio de Mesquita Filho" (Campus de Botucatu). Faculdade de Ciências Agronômicas. IV. Título. 


\title{
UNIVERSIDADE ESTADUAL PAULISTA "JÚLIO DE MESQUITA FILHO" FACULDADE DE CIÊNCIAS AGRONÔMICAS \\ CAMPUS DE BOTUCATU

\author{
CERTIFICADO DE APROVACĀO
}

\begin{abstract}
TITULO: A COMUNIDADE DE BORBOLETAS FRUGIVORAS DE ÁREAS EM PROCESSO DE RESTAURAÇÃO, FRAGMENTOS DE FLORESTAS ESTACIONAL SEMIDECIDUAL E PASTAGENS.
\end{abstract}

ALUNA: PAULA RACHEL ROTTA FURLANETTT

ORIENTADORA: PROFA. DRA. VERA LEX ENGEL

CO-ORIENTADOR PROF, DR, MARCIO UEHARA-PRADO

Aprovado pela Comissäo Examinadora
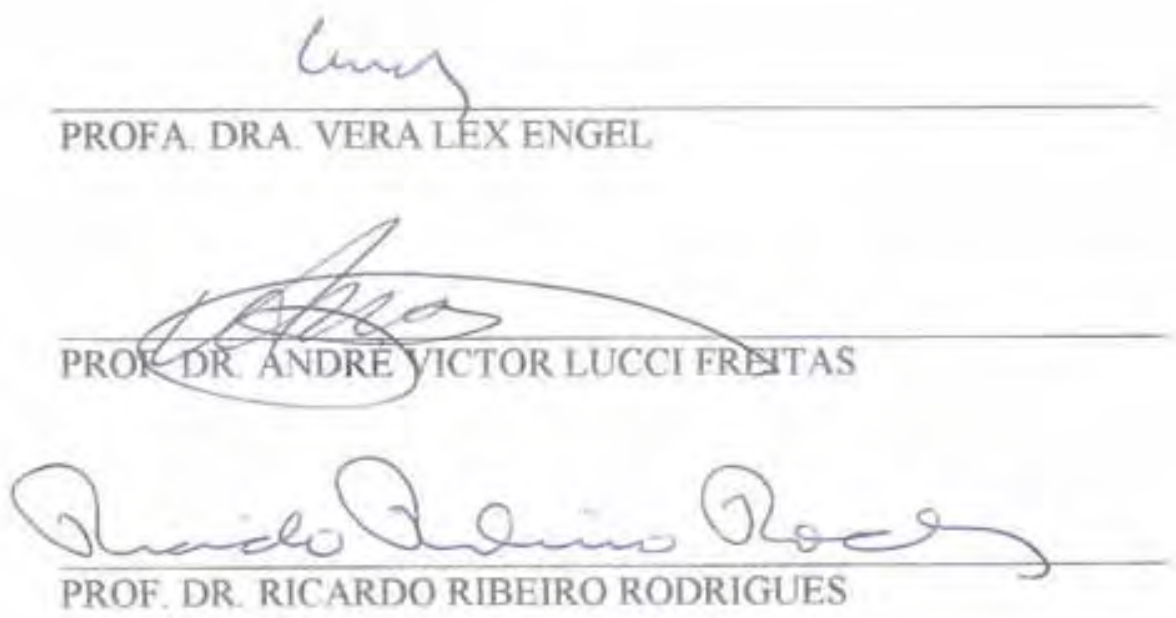

Data da Realização: 02 de março de 2010 


\section{AGRADECIMENTOS}

Á Universidade Estadual de São Paulo, FCA/UNESP, e ao departamento de Ciência Florestal, pela oportunidade e apoio por este trabalho.

Á FAPESP, pela concessão da bolsa de mestrado, e por incentivar e acreditar desde o projeto ao fim deste trabalho.

À Prof. Dr ${ }^{\mathrm{a}}$. Vera Lex Engel, pela orientação e confiança, e mais do que isso, um exemplo de vida, além do incentivo e momentos de amizade.

Ao meu queridíssimo Co-Orientador Dr. Márcio Uehara-Prado, pela sua juventude e ânsia de viver, que desde o inicio me acompanha, nos entendendo ou não, trabalhamos juntos.

Ao Prof. Dr. André V.L. Freitas que desde o primeiro contato até hoje, fez de um sonho meu a mais pura realidade.

Aos funcionários da faculdade, aos motoristas (em destaque o Jaime), ao Dicão pela "força", à Lurdinha e à Silvia queridas, que estão sempre prontos a nos ajudar.

Ao Elder, que sem palavras para agradecer agradeço, por cada momento, imprescindível ir a campo sem ele, e pelos momentos de risadas, descontrações e também aos de tensão, onde aprendi muito a viver.

A Prof. Dr ${ }^{\mathrm{a}}$. Renata C. B. Fonseca, pelas poucas vezes, porém essências ao meu trabalho e hoje a minha vida.

Aos meus pais, Renato e Fátima, que nunca me deixaram a sós, e que acreditam e incentivam a minha Vida, "metade desse amor, foram eles que me deram". Eles são a causa e consequiência de tudo. Simplesmente Amo.

Ao meu exemplar "namorido" Rubens, por jamais ter desacreditado em mim e por sua "força de pedra" suportar a minha de "Onda do Mar", e assim juntos vivemos nossos dias de "aprendizes e fazedores" Felizes. E por hoje estarmos no mesmo barco. Amo.

Aos meus tios (Lucas, Mateus, João, Marcus, Regina e Tio Roger) primos, aos meus avôs que de longe me olham e a minha vó Noemia que me benze de onde estiver.

Aos meus irmão, que...putz....falar de irmãos......, não tenho palavras, muito obrigada a vocês meus amores que me sinto feita de um pouco de cada um e que jamais passaram a mão na minha cabeça por convenção, e que sempre estão ao meu lado e me entendem como sou, é a minha força de cada manhã. Amo.

Á família do Rubens, que com todos eles eu caminhei para chegar onde cheguei. A Dona Mira que é a inspiração do Rubens, sempre, sempre me fez sentir bem. Ao meu Sogrão Nuna, que divertidamente me dá exemplos de vida e a minha Sogra Cláudia pela sua força de batalha nos ensina a não desistir dos nossos sonhos.

Á "belinosa" que sem ela, sinceramente, nada teria acontecido e nem teria sido como foi! Sem falar que ela merece o carinho de todos e uma ajuda de custo rsrsrs!

Á todos os meu parceiros de campo, o Mussum, a Hã, a Zuca, Bezzera, Guadua, Zé Butina, Nukco, Curisco e Cia, Yodô e a todos do Lerf (Laboratório de Ecologia e Restauração Florestal) que sempre prontos me apoiaram e ajudaram. 
Ás minhas amigas Felícia (Beatriz Rosângela) e Taboa (Ana Maria), que pela força, incentivo, "ombro amigo", conselhos e até o silencio de cada uma me fez crer e continuar, aprendi um pouco mais sobre a Vida.

A minha amiga Elen, que foi uma pessoa presente, companheira e um pouquinho de mãe, e a toda sua família que sempre estavam a disposição, e que até hoje estão ao meu lado.

À minha amiga Rê (Renata Rodrigues), por meu acolhimento em sua vida, fez da minha, mais suave. E a Minha amiga Mila, pelas suas palavras, duras ou compreensivas, pelos choros e risadas, estou aqui hoje e assim.

Á Teia, Tetéia ou mesmo Liziete Ribeiro, não sei como descrevê-la, foi minha ajudante, mãe, irmã, amiga, mora no meu coração, a distancia nos separou, mais tenho certeza que não nos afastará. Sou grata a tudo, desde os paieirinhos depois do almoço às noites em claro. Amo.

Aos amigos distantes, os próximos, aos ausentes e os persistentes, obrigada por estarem sempre comigo.

Ao IBAMA por nos permitir e acreditar nesta pesquisa.

A todas as pessoas envolvidas neste trabalhos, como ao Seu João e sua esposa pela fidelidade dos caldos de cana e Dona da quitanda que separou todas as bananas nanicas para este trabalho e a Dona Carmem nossa costureira fiel, que me ajudou com as armadilhas. Obrigada a todos vocês.

A todos os professores e pessoas que contribuíram a minha vida e às que eu possa ter injustamente suprimido nestes agradecimentos. 
MATANÇA

"Cipó caboclo tá subindo na Virola chegou a hora do Pinheiro balançar

Sentir o cheiro do mato da imburana

Descansar morrer de sono na sombra da Barriguda

De nada vale tanto esforço do meu canto Prá nosso espanto tanta mata ah já vão matar

Tal Mata Atlântica e a próxima Amazônia Arvoredos seculares impossivel replantar

Que triste sina teve Cedro nosso primo Desde menino que nem gosto de falar

Depois de tanto sofrimento seu destino Virou tamborete, mesa, cadeira, balcão de bar

Quem por acaso ouviu falar da Sucupira

Parece até mentira que o Jacarandá

Antes de virar poltrona, porta, armário

Moro no dicionário vida eterna milenar

Quem hoje é vivo corre perigo

E os inimigos do verde da sombra o ar

Que se respira e a clorofila

Da mata virgem destruída vão lembrar

Que quando chegar a hora é certo que não demora Não chame Nossa Senhora só quem pode nos salvar

Caviuna, Cerejeira, Baraúna, Imbuia, Pau-d'alho, Solva, Juazeiro e Jatobá Gonçalo Alves, Paraíba, Itaúba, Louro, Ipê, Paracaúba,Peroba,Maçaranduba Carvalho, Mogno, Canela, Imbuzeiro,Catuaba, Janúba, Aroeira, Araribá, Pau-ferro, Anjico, Amargoso, Gameleira, Andiroba, Copaíba, Pau-Brasil, Jequitibá Quem hoje é vivo, corre perigo."

(XANGAI) 
SUMÁRIO

Páginas

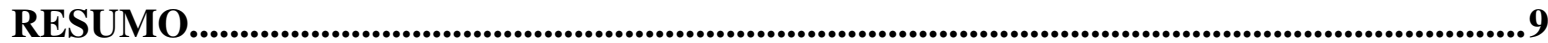

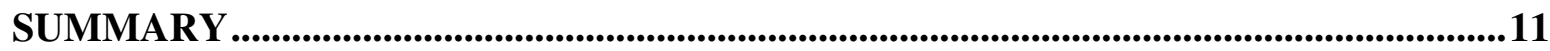

1.INTRODUÇÃ

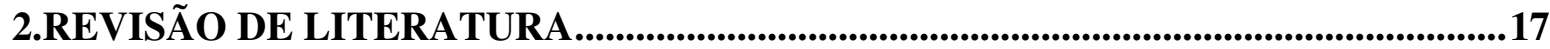

2.1 A Mata Atlântica e o processo de fragmentação ……...............................................17

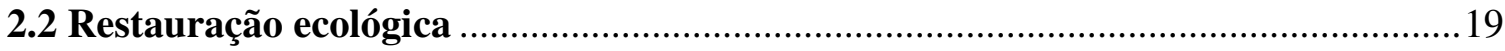

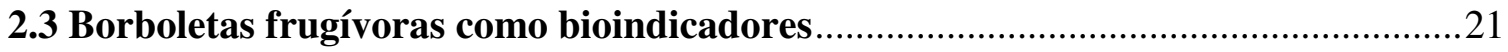

3. MATERIAL E MÉTODOS

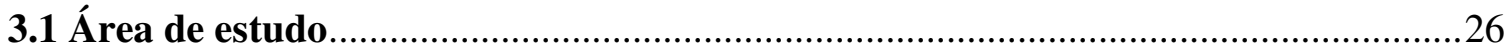

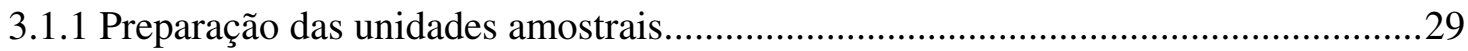

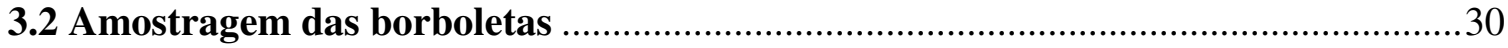

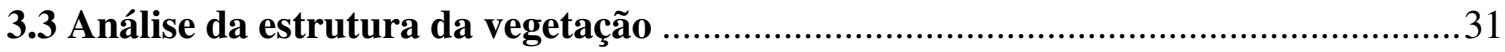

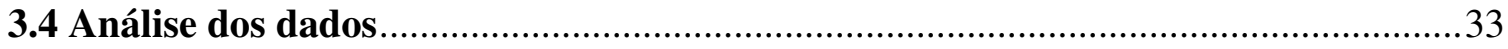

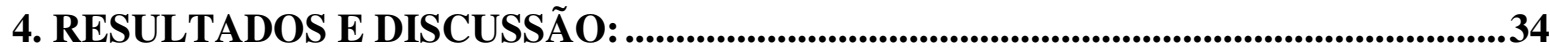

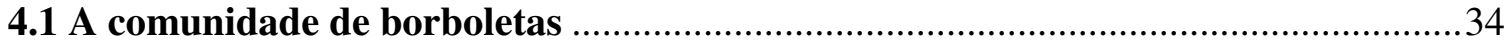

4.1.1 Abundância, Riqueza e Diversidade de espécies entre os tratamentos .....................35

4.1.2 Composição de espécies de borboletas frugívoras .................................................39

4.2 Qualidade do habitat e relação com a comunidade de borboletas frugívoras ..........47

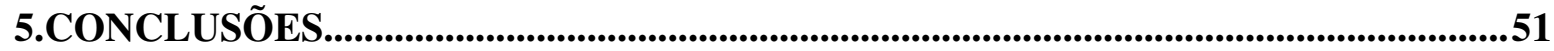

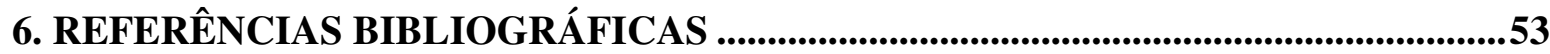




\section{LISTA DE TABELAS}

Tabela 1 Número de espécies, abundância e índices de diversidade para do levantamento de borboletas frugívoras realizado em cada tratamento durante as coletas de Nov/2008 a maio/2009.

Tabela 2 Total da Abundância e Riqueza de espécies das subfamílias de borboletas frugívoras pertencentes à família Nymphalidae dos três tratamentos (fragmento, restauração e pasto) nas Fazendas experimentais Lageado e Edgárdia (SP) de novembro de 2008 a maio de 2009.

Tabela 3 Lista de espécies de lepidópteros da família Nymphalidae coletadas em cada tratamento: fragmentos (Frag), pastagens (Past) e restauração (Rest), no período de nov/2008 a maio/2009.

Tabela 4 Tabela das médias para cada variável ambiental amostrada nos tratamentos, onde d.p. é o desvio padrão para cada média:

Tabela 5 Coeficientes de correlação parcial (Cfcrp) das análises de regressão múltipla do tipo stepwise para a variável dependente $\mathrm{N}$ (número de espécies borboletas frugívoras). 


\section{A COMUNIDADE DE BORBOLETAS FRUGÍVORAS DE ÁREAS EM PROCESSO DE RESTAURAÇÃO, FRAGMENTOS DE FLORESTA ESTACIONAL SEMIDECIDUAL E PASTAGENS. Botucatu, 2010. 68 p. Dissertação (Mestrado em Ciências Florestais) - Faculdade de Ciências Agronômicas, Universidade Estadual Paulista. \\ Autora: PAULA RACHEL ROTTA FURLANETTI \\ Orientadora: VERA LEX ENGEL \\ Co-orientador: MARCIO UEHARA-PRADO}

\section{RESUMO}

A fragmentação da paisagem resultante das ações antrópica gera inúmeras conseqüências, sendo delas a mais grave a perda da biodiversidade. A restauração ecológica tem como objetivo levar um ecossistema degradado a um estado mais próximo possível daquele anterior aos distúrbios. As borboletas frugívoras são consideradas como ótimos insetos bioindicadores. Para se avaliar os esforços da restauração, faz-se necessário o monitoramento dessas áreas, através de bioindicadores. $\mathrm{O}$ objetivo deste trabalho foi avaliar a comunidade de borboletas frugívoras de áreas em processo de restauração, comparando a fragmentos de floresta nativa e a áreas degradadas (pastagem), para confirmar a hipótese de que a composição e distribuição de borboletas frugívoras (Nymphalidae) nas áreas em processo de restauração estão mais próximas às características da comunidade dos fragmentos da região do que das áreas de pastagens. O estudo foi realizado em três sítios diferentes, onde foram avaliados 3 tratamentos: uma área de pastagem (matriz), um fragmento florestal e uma área de plantio misto com espécies nativas (plantios realizados há 11 anos, visando à restauração florestal da área). As coletas dos indivíduos foram feitas em armadilhas atrativas, considerando-se um conjunto de cinco armadilhas em linha como uma unidade amostral por tratamento (Restauração, Fragmento e Pasto), em cada sítio amostral (1, 2 e 3). Foram analisadas a abundância e riqueza observada de espécies, a riqueza esperada pela curva de rarefação e a distribuição e composição das espécies para cada tratamento. Foram calculados os índices de diversidade de Shannon-Wiener e de alfa de Fisher e eqüidade de Pielou.. As amostras foram comparadas entre si através de análise de agrupamento pelo método de BrayCurtis, e por análise de correspondência utilizando o programa PAST. Foram feitas análises de regressão múltipla "stepwise” para correlacionar as características ambientais com abundância 
e riqueza de espécies de borboletas. Foram coletados 978 indivíduos, distribuídos em 48 espécies, representadas por 6 subfamílias de Nymphalidae. A composição e abundância de espécies de borboletas foram diferentes para cada tratamento (fragmento, restauração e pasto), sendo que a maior riqueza total e abundância foram encontradas nas áreas em restauração e a menor nas pastagens. As áreas em restauração foram mais semelhantes às áreas de fragmentos do que às de pastagens quanto à composição de espécies. Dentre as espécies com $\mathrm{N} \geq 20$, as espécies que foram comuns entre restauração e fragmentos e ausentes na pastagem foram respectivamente Hamadryas epinome (Biblidinae), P. phronius (Satyrinae), P. poltis (Satyrinae), C. selima (Biblidinae) e T. virgilia (Satyrinae). A espécie Callicore sorana foi a mais abundante de todas as espécies $(\mathrm{N}=129)$, sendo esta a mais abundante na pastagem e ausente nos fragmentos. A composição de espécies de borboletas das áreas de restauração diferiu entre os três sítios de restauração, porém a diversidade foi a mesma, mostrando que a restauração ecológica segue por trajetórias sucessionais diferentes, dependendo das características da paisagem e vizinhança. A abundância de borboletas não se correlacionou significativamente a $5 \%$ com as variáveis ambientais do habitat, mas o número de espécies (N) se correlacionou negativamente com a densidade de vegetação herbácea $(p=0,003)$ e positivamente com a densidade de cobertura de copas $(\mathrm{p}=0,037)$. As áreas em restauração podem ser consideradas como uma transição entre matriz de pastagens e fragmentos florestais, sendo importantes para conservação da biodiversidade e formação de corredores ecológicos. Representantes da subfamília Morphinae podem ser considerados como indicadores de habitats mais bem estruturados e complexos (fragmentos), e espécies da subfamília Satyrinae, Charaxinae e Biblidinae como indicadores de habitats intermediários, como as áreas em restauração. O estudo da guilda de borboletas frugívoras mostrou dados consistentes e satisfatórios para os objetivos do trabalho, merecendo mais pesquisas quanto a espécies indicadoras potenciais de qualidade de habitat e de reestruturação de comunidades em restauração.

Palavras chave: Restauração ecológica, borboletas frugívoras, indicadores de restauração, Nymphalidae; floresta estacional semidecidual. 


\section{ASSEMBLAGES OF FRUIT-FEEDING BUTTERFLIES OF RESTORED SITES, SEASONAL SEMIDECIDUOUS FOREST FRAGMENTS AND PASTURES. Botucatu, 2010. 68 p. Dissertação (Mestrado em Ciências Florestais) - Faculdade de Ciências Agronômicas, Universidade Estadual Paulista. Author: PAULA RACHEL ROTTA FURLANETTI Adviser: VERA LEX ENGEL Co-adviser:: MARCIO UEHARA-PRADO}

\section{SUMMARY}

The landscape fragmentation resulting from the human actions generates countless consequences, among them the most serious is the biodiversity loss. Ecological restoration has as objective taking a degraded ecosystem back to a state as close as possible to that previous to the disturbances. To evaluate the effectiveness of restoration efforts it is necessary the monitoring of those areas by means of indicators. The fruit-feeding butterflies are considered as good bioindicator insects. This research aimed at evaluating the fruit-feeding butterflies (Nymphalidae) community of ecosystems in restoration process in comparison with the neighboring native forest fragments and grasslands (pastures). The study was settled at 3 different sites where mixed tree restoration plantings were established 11 years ago. The butterflies surveys were made using attractive traps, considering a group of 5 five traps in line as one sampling unit for each treatment (Restoration, Fragment and Pasture) in every one of the three study sites (1,2 and 3). The data were analyzed to verify the diversity patterns and expected species richness within the habitats in each treatment. We also estimated Shannon-Wiener's and Fisher's alpha diversity indexes and Pielou's Equitability. The expected richness was estimated by rarefaction curves. The samples were compared by BrayCurtis' cluster analysis and correspondence analysis. Stepwise multiple regressions were made to correlate the environmental characteristics with butterfly abundance and species richness. A total of 978 individuals were collected, distributed within 48 species, representing six subfamilies of Nymphalidae. Concerning the species composition of the fruit-feeding butterfly assemblages, we found differences among treatments, were the highest richness and abundance were found in restoration areas and the smallest ones in the pasture areas. The species composition of restoration areas was more similar to the forest fragments than the 
pastures. Among the species with $\mathrm{N} \geq 20$, Hamadryas epinome (Biblidinae), P. phronius (Satyrinae), P. poltis (Satyrinae), C. selima (Biblidinae) e T. virgilia (Satyrinae). Were common to both restoration areas and forest fragments and were absent in the pastures. Callicore sorana was the most abundant among all species $(\mathrm{N}=129)$, being representative of the pastures and absent in the forest fragments. Butterfly assemblages in restoration areas differed among sites, but the species richness was similar, indicating different trajectories between them and depending on the landscape and neighborhood context. Butterfly abundance did not correlate significantly at $5 \%$ with habitat environmental variables, but the number of species $(N)$ was negatively correlated with herbaceous vegetation density of $(p=0,003)$ and positively with canopy cover density $(\mathrm{p}=0,037)$. Restored areas are clearly defined as intermediate between the pasture and forest fragments areas, permitting to affirm that they can be considered as ecotones between pasture and fragments, important for landscape connection and biodiversity conservation. Representatives of the subfamily Morphinae can be considered better as indicators of habitats structured and complex (fragments), and species of the subfamily Satyrinae, Charaxinae and Biblidinae as indicators of intermediate habitats, as the areas in restoration. The fruit-feeding butterfly guild showed up data robust and satisfactory for the objective of this work, deserving further research concerning potential indicator species for habitat quality and community reassembly in restored areas.

Key Words: Ecological restoration, fruit-feedings butterflies, restoration indicators, Nymphalidae; seasonal semideciduous forest. 


\section{INTRODUÇÃO}

O desenvolvimento da civilização tem levado à modificação da paisagem e à fragmentação florestal. Muitos biomas estão passando por processos de desflorestamento por motivos variados, o que tem causado muitas discussões sobre os problemas que poderão surgir a partir desta destruição. Florestas extensas estão sofrendo grandes consequiências ecológicas devido a fragmentação, como alteração na composição e na dinâmica das comunidades, nas interações tróficas e nos processos ecossistêmicos (LAURANCE et al., 2009). A Mata atlântica é considerada um dos mais importantes biomas do mundo, abrigando uma elevada diversidade com altos índices de endemismos (MITTERMEIER et al., 2004 e MYERS et al., 2000), hoje sendo um dos ecossistemas mais ameaçados devido ao processo de fragmentação (MYERS et al., 2004)

O processo de fragmentação pode ser entendido como a divisão de habitats que anteriormente ocupavam grandes áreas em inúmeros pedaços remanescentes desconectados, inseridos em uma matriz inóspita formada por diversos tipos de sistemas como monoculturas, cidades ou por outras atividades humanas (PRIMACK \& RODRIGUES 2001). Este processo de fragmentação gera como consequiência direta a redução da biodiversidade e a diminuição no tamanho das populações, aumentando o risco de extinções. 
A região de Botucatu, SP, também passou por um processo histórico de exploração que deixaram marcas na paisagem de hoje. Muitos estudos têm sido feitos nessa região para estudar as possíveis consequências da fragmentação, conhecer sua biodiversidade e dar bases para a sua conservação e restauração, como estudo da mastofauna em CAES (2009), aspectos fitossociológicos e silvigenéticos (CASSOLA, 2008), análise estrutural da vegetação (FONSECA \& RODRIGUES, 2000), levantamento da entomofauna (LEITÃOLIMA et al, 2002) e de dispersão de sementes pela avifauna (ROSA, 2003), entre outros (ORTEGA \& ENGEL, 1992, GARCIA, et al., 2003, JORGE \& SARTORI, 2002, ENGEL\& PARROTA, 2001).

Com intenção de reverter o processo de fragmentação, e diminuir seus efeitos negativos, a restauração ecológica proporciona condições para que a fauna e flora recuperem sua integridade estrutural e funcional. São necessários incentivos a projetos de restauração ecológica, na tentativa de mitigar as conseqüências negativas da fragmentação, procurando atribuir benefícios à sociedade e para o meio ambiente, almejando um menor custo de instalação e manutenção.

Ecologia da Restauração é a ciência na qual a prática de restaurar um ecossistema se apóia (SOCIETY FOR ECOLOGICAL RESTORATION INTERNATIONAL, 2004) e visa a reconstrução das complexas interações ecológicas do ecossistema, com base no conhecimento dos processos de formação natural dos remanescentes (RODRIGUES \& GANDOLFI, 2004).

A restauração ecológica pode ser entendida ainda, segundo a Society for Ecological Restoration, como "a ciência, prática e arte de assistir e manejar a recuperação da integridade ecológica dos ecossistemas, incluindo um nível mínimo de biodiversidade e de variabilidade na estrutura e no funcionamento dos processos ecológicos, considerando-se seus valores ecológicos, econômicos e sociais”, diferindo dos termos de recuperação e reabilitação pelas metas e objetivos e a escala de tempo adotada como futuro (ENGEL \& PARROTTA, 2003).

Em 1998 foi iniciado um projeto que tinha como objetivos testar a sustentabilidade ecológica, econômica e social de diferentes modelos de associações de espécies nativas, visando a restauração de ecossistemas degradados da Mata Atlântica 
(Floresta Estacional Semidecidual), através de convênio entre a UNESP/FCA e o USDAForest Service, EUA (ENGEL \& PARROTA, 2001).

Para que os objetivos da restauração sejam atingidos, espera-se que estas áreas tenham atingido um grau de complexidade semelhante a ecossistemas de referência, como fragmentos florestais. Atualmente, buscam-se indicadores de sucesso que possam funcionar como parâmetros para o monitoramento dessas áreas em processo de restauração, que sejam capazes de prever o desenvolvimento futuro da comunidade e demonstrar este grau esperado.

Borboletas têm sido freqüentemente utilizadas como indicadores da conservação de habitats (UEHARA-PRADO et al., 2009), dentre outros grupos de insetos que são afetados pela fragmentação florestal (UEHARA-PRADO et al., 2005).

Devido à sua facilidade de amostragem, sua taxonomia e sistemática bem definidas, seu tamanho relativamente grande e suas cores atraentes que as tornam carismáticas (DAILY \& EHRLICH, 1995; UEHARA-PRADO et al., 2005) tornam as borboletas frugívoras boas indicadoras, além de demonstrar uma associação estreita com a abundância de plantas hospedeiras, microclima e padrões de disponibilidade de recursos (BARLOW et al., 2007) e uma grande associação com estrutura e composição da vegetação (KREMEN et al., 1993; NEW et al., 1995).

Estas características fazem das borboletas um dos grupos de insetos mais bem conhecidos, e com um grande potencial para elucidar os padrões de diversidade e conservação de insetos e de seus habitats (DEVRIES et al., 1997). Dos vários grupos de borboletas da família Nymphalidae, alguns grupos têm sido apontados como bastante informativos e úteis para a avaliação rápida de condições ambientais, segundo FREITAS et al., (2003).

Considerando o potencial das borboletas como indicadoras de mudanças no hábitat e as metas da restauração ecológica, o objetivo deste trabalho foi avaliar a comunidade de borboletas frugívoras de áreas em processo de restauração, comparando a fragmentos de floresta nativa e a áreas degradadas (pastagem), para confirmar a hipótese de que a composição e distribuição dessa comunidade nas áreas em processo de restauração estão mais próximas às características da comunidade dos fragmentos da região do que das áreas de pastagens. 
Pretendeu-se responder às seguintes questões:

1) Existem diferenças na composição e abundância de espécies de borboletas entre os fragmentos de floresta nativa, áreas em restauração e pastagem?

2) Pode-se usar espécies de borboletas frugívoras como indicadoras de áreas em processos de restauração? 


\section{REVISÃO DE LITERATURA}

\subsection{A Mata Atlântica e o processo de fragmentação}

A estabilidade de um ecossistema depende dos fluxos de energia, da biodiversidade e dos processos de ciclagem dos nutrientes. $\mathrm{O}$ gradativo crescimento humano com uso excessivo de recursos naturais juntamente à expansão agropecuária resultam na degradação dos ambientes e no crescente aparecimento de fragmentos isolados por paisagem antrópicas (LOUZADA, 2000).

Os biomas tropicais possuem uma característica peculiar, destacandose o contínuo norte-sul da Matas Atlântica (AB'SÁBER, 2003). Segundo o Mapa de Vegetação do Brasil do IBGE/MMA (2003), a Mata Atlântica é formada por: floresta ombrófila densa atlântica, floresta ombrófila mista, florestas estacional semidecidual, floresta estacional decidual e para AB’SÁBER (2003), caracterizam pelas diferentes subáreas topográficas que vão desde os tabuleiros da Zona da Mata nordestina até as escarpas tropicais das Serras do Mar e Mantiqueira e " mares de morros".

No interior do Estado de São Paulo, a Mata Atlântica penetra com fortes irregularidades de florestas tropicais de planaltos, de cerrados e cerradões e de lajeados 
nos cumes das serras como as emergências rochosas das cuestas, como na região de BotucatuSP, com grandes manchas dispersas de solos ricos e influências orográficas na Serra do Mar, Mantiqueira e escarpas de cuestas arenítico-basalticas, que garantem a presença de florestas biodiversas (AB'SÁBER, 2003).

A Mata Atlântica possui uma longa história de degradação desde o período colonial com início da exploração do pau-brasil, com o desenvolvimento da agricultura, e por intensos e desordenados processos de urbanização, desmatamento em áreas declivosas e expansão agrícola. (GONÇALVES et al., 2003). Os resultados de tantos anos de exploração das áreas geraram hoje um mosaico com menos de 8,0\% de florestas remanescentes isolados (RESERVA, 2009).

A perda de habitat e a redução de áreas naturais causadas pelas atividades antrópicas são as principais ameaças para a biodiversidade e a conservação das espécies (SAWCHIK et al., 2002). A fragmentação florestal afeta de diferentes maneiras diversos grupos de organismos, alterando a riqueza, a abundância e a composição de espécies, a dinâmica florestal, a estrutura trófica da comunidade e uma variedade de processos ecológicos (LAURANCE et al., 2001, FAHRIG 2003). A estrutura e a dinâmica de um fragmento florestal variam em função de uma série de fatores, principalmente o histórico de perturbação, a forma, a área do fragmento, o tipo de vizinhança e o grau de isolamento

O isolamento afeta a movimentação de muitas espécies e a dinâmica das metapopulações, e consequientemente as taxas de colonização dos fragmentos por diferentes taxa, efeitos esses minimizados com os corredores de vegetação, os pontos de ligação, os "stepping stones" (pequenas áreas de hábitat dispersos na matriz) inseridos na matriz (METZGER, 1999 e LOUZADA, et al., 2001). A diminuição do fluxo de indivíduos entre populações pode aumentar a taxa de endogamia, exogamia e evitar o efeito resgate (PRIMACK \& RODRIGUES, 2001).

Como conseqüência da atual dinâmica de uso da terra pelo homem causando modificação e/ou destruição do habitat, fato que causa o aumento assustador das taxas de desmatamento (MYERS, 1988), um outro problema sério que ocorre como processo de fragmentação são as inúmeras áreas cultivadas depois de muitos anos de uso inadequado do solo, que são abandonadas por se tornarem ambientes degradados e improdutivos. Desta forma, como áreas degradadas são aquelas que após um distúrbio, perderam suas possíveis 
formas de regeneração natural (KAGEYAMA et al., 1992) e suas características físicas, químicas e biológicas (SOUZA, 2000), apenas a proteção dos remanescentes florestais muitas vezes não seria suficientes para a sua conservação, sendo necessários esforços para a restauração desses ambientes degradados ou perturbados (ENGEL \& PARROTTA, 2003).

\subsection{Restauração ecológica}

A restauração ecológica tem evoluído como ciência no Brasil desde a década de 70 do século XX. Entretanto, bases científicas foram introduzidas no país apenas no final da década de 1980, onde se iniciou a discussão nos meios acadêmicos relativos a estudos científicos voltados às práticas sobre o comportamento de espécies nativas, em reflorestamentos mistos e em recuperação de áreas degradadas (GONÇALVES et al., 2005).

A restauração é uma atividade intencional que inicia ou acelera a recuperação de um ecossistema quanto à sua saúde, integridade e sustentabilidade. $\mathrm{O}$ ambiente recriado deve ser um ecossistema regulado totalmente por processos naturais e com a estrutura e funcionalidade o mais próximo possível das comunidades naturais, levando em conta a interdependência e interações da flora e da fauna entre elas e com o meio abiótico, visando atingir os objetivos da reparação ambientais em longo prazo. Esta pode ser considerada completa quando o ecossistema sob manipulação descreve a trajetória desejada e não mais precisar do manejo (ALMEIDA, 1996; ENGEL \& PARROTA, 2003; SOCIETY FOR ECOLOGICAL RESTORATION INTERNATIONAL, 2004).

O grande desafio é fazer com que ambientes restaurados assumam gradualmente características próximas de florestas naturais, exercendo interações e funções ambientais, como proteção de nascentes e principalmente a interligação dos fragmentos florestais remanescentes (RODRIGUES et al., 2009). Outro desafio está no sentido de iniciar um processo de sucessão o mais semelhantemente possível com os processos naturais, formando comunidades com biodiversidade que tendam a uma rápida estabilização e restabelecimento das interações bióticas (REIS et al., 2003). A habilidade do ecossistema restaurado em manter sua trajetória apesar dos estresses (distúrbios sofridos) vem da sua resistência e resiliência (SOCIETY FOR ECOLOGICAL RESTORATION INTERNATIONAL, 2004). 
Com este enfoque, acredita-se que o sucesso de um plantio com espécies nativas, voltado à restauração do ecossistema, depende basicamente do conhecimento dos processos chave que condicionam a estrutura e o funcionamento do ecossistema, bem como dos mecanismos que estão impedindo ou dificultando a regeneração natural da vegetação nativa (ENGEL \& PARROTTA, 2003), além da diversidade genética, dos ciclos biogeoquímicos e até da sustentabilidade econômica das iniciativas de restauração (RODRIGUES et al., 2009).

A saúde da biota, ou sua integridade, podem ser inferidos através da avaliação contínua dos recursos naturais, diversidade e riqueza dos organismos com suas interações e estudos dos processos ecológicos e de fluxo de energia destes sistemas. Para isso, podem ser selecionadas espécies ou grupos de espécies que funcionem como representantes de outros organismos e de processos, fornecendo informações importantes para conservação efetiva e o uso sustentável dos recursos naturais, atividade esta conhecida como monitoramento ambiental in situ ou bioindicação. (BROWN, 1997; FREITAS et al., 2003 e 2006 ; LEWINSOHN et al., 2005).

Unidades de conservação e ecossistemas restaurados devem ser ambientes íntegros e funcionais; entretanto não se sabe qual a porcentagem de espécies e processos que estes ecossistemas preservam ou conservam (ENGEL E PARROTA, 2003 e LEWINSOHN et al., 2005). Ecossistemas são diferentes e por esta razão nenhum ecossistema restaurado pode ser idêntico ao de referência, nem tampouco devam seguir a mesma trajetória para chegar ao objetivo do projeto. Entretanto, os objetivos da restauração são atingidos por meio de metas específicas e as metas da restauração podem ser avaliadas por critérios de sucesso; estes critérios são concebidos em grande medida a partir da compreensão dos ecossistemas de referência (SOCIETY FOR ECOLOGICAL RESTORATION INTERNATIONAL, 2004).

As avaliações de áreas em processos de restauração abrangem aspectos mais amplos do que apenas critérios puramente fisionômicos; os indicadores de restauração devem avaliar não só a recuperação visual da paisagem, mas também a reconstrução dos processos ecológicos mantedores da dinâmica vegetal (RODRIGUES E GANDOLFI, 2004). A restauração só pode ser considerada bem sucedida se as inter-relações entre o meio físico e 
biótico forem restabelecidas, incluindo aí as interações interespecíficas (REIS $\mathrm{E}$ KAGEYAMA, 2003).

Outros parâmetros para avaliação das áreas em restauração já foram sugeridos como indicadores de processos e dinâmica por muitos autores, como a presença de formigas (RUIZ-JAÉN E AIDE, 2005), mamíferos de médio e grande porte (CAES, 2008), de entomofauna (LEITÃO-LIMA, 2002), de avifauna (ROSA, 2003) e de morcegos e aves (PARROTA et al., 1997)

Neste contexto, MAJER (1989) sugere que o destino e a sucessão da restauração estão intimamente ligados à fauna de invertebrados e vertebrados. Em trabalhos de restauração, os estudos enfocando vertebrados têm uma razão de $3 / 2$ em relação aos de invertebrados, concentrando-se em pássaros, mamíferos e répteis. Entretanto, dentre os invertebrados os lepidópteros têm recebido uma maior atenção, seguidos das formigas e dos besouros, por serem espécies ícones para os quais consideráveis dados ecológicos e de distribuição estão disponíveis e por muitos deles serem conhecidos e por estarem ameaçados de extinção. Assim, a avaliação de áreas em processos de restauração, utilizando invertebrados como bioindicadores, deve ajudar na maior compreensão das mudanças de cenários de restauração (MAJER, 2009).

\subsection{Borboletas frugívoras como bioindicadores}

As borboletas e mariposas contribuem para os processos essenciais dos ecossistemas como a polinização, herbivoria e decomposição (LOMOV et al., 2006). O termo borboletas frugívoras representa os indivíduos adultos da família Nymphalidae, conhecidas por serem atraídas e se alimentarem de frutos e animais em decomposição, além de excrementos e exudatos de plantas (DEVRIES et al., 1997).

São facilmente amostradas usando o método de armadilhas atrativas com iscas (DEVRIES, 1988 e PINHEIRO \& ORTIZ, 1992). Assim, em amostragens simultâneas o esforço pode ser padronizado em diferentes áreas, além de que os indivíduos podem ser soltos depois de identificado com um mínimo de manuseio, permitindo um estudo não destrutivo (UEHARA-PRADO et al., 2004; FREITAS et al., 2004). Além disso, a atração das borboletas pela isca reduz a possibilidade de capturas ao acaso (FREITAS et al., 2003). 
As borboletas frugívoras podem compor entre 40 a $55 \%$ do total da riqueza das Nymphalidae de florestas tropicais (DEVRIES, 1987). Cerca de dois terços das espécies de borboletas brasileiras estão representados pelas espécies da região de Mata Atlântica, possuindo muitas espécies raras e de maior dificuldade de serem amostradas (BROWN, 1996).

A diversidade do território brasileiro, em destaque as regiões de florestas tropicais, abrigam inúmeros grupos de organismos propostos a serem usados como indicadores de muitos atributos e parâmetros (BROWN, 1997) para conservação.

Porém, segundo UEHARA-PRADO (2003) e FREITAS et al., (2006), qualquer espécies "indica” a existência de um conjunto particular de condições ambientais ás quais se adaptou ao longo do processo evolutivo. Deste modo, qualquer alteração que cause a desestruturação destas condições provoca uma resposta nos organismos, que pode ser desde a eliminação total de espécies até o favorecimento das mesmas (BROWN, 1991). Assim, tornase importante a escolha do indicador correto.

A escolha errada de uma espécie ou o uso inapropriado do bioindicador pode trazer sérias e negativas conseqüências, havendo a necessidade de estudos rigorosos nesse sentido (LINDENMAYER, 1999).

FREITAS et al. (2006), cita 10 critérios propostos pela combinação de critérios de outros autores para se escolher um indicador biológico adequado. Os critérios são: taxonomia relativamente bem resolvida; conhecimento biológico; diversidade conveniente; ciclo de vida curto; diversidade ecológica; fidelidade de habitat; associação estreita com recursos ou outras espécies; "sedentarismo" relativo; fidelidade na amostragem, triagem e identificação e pouco uso humano.

A princípio, os biólogos usavam os vertebrados e plantas superiores como bons indicadores biológicos, mas de acordo com estes critérios, as espécies mais “carismáticas", hoje não são as mais visadas, passando a serem os invertebrados como grupos de grande potencial (BROWN, 1997 e LEWINSOHN et al., 2005). Dentre os invertebrados usados como indicadores, os insetos têm se destacado, pois respondem rapidamente praticamente a qualquer tipo e intensidade de alteração ambiental e muitas vezes refletem a sua própria condição de conservação e a de outros grupos. 
Segundo BROWN, (1997), dependendo do tipo de informação procurada, da importância de cada grupo no ambiente estudado e da habilidade do monitor, os grupos podem ter mais ou menos utilidade e confiança quanto aos resultados obtidos, dentre os quais as borboletas frugívoras se destacam junto com os besouros e formigas em características que atendem a estes critérios (BROWN, 1991; ACCACIO et al., 2008),)

LEWINSOHN et al., (2005) explicam que, nos estudos de bioindicadores para a avaliação e monitoramento de habitats, entre os diferentes grupos taxonômicos que fornecem informações importantes para a conservação, as borboletas são as mais representadas. Ressaltam ainda que em geral invertebrados de ciclos de vida mais longos apresentam respostas demográficas e dispersivas mais lentas que os de ciclo de vida curtos. Este grupo é relativamente conspícuo e fácil de amostrar e identificar, além de demonstrar uma associação estreita com a abundância de plantas hospedeiras, microclima e padrões de disponibilidade de recursos (BARLOW et al., 2007).

BOUYER et al., (2007), relataram, com base em uma vasta revisão, que as relações entre distúrbio de ecossistemas e insetos têm sido estudadas em florestas tropicais, afirmando que borboletas frugívoras se mostraram sensíveis a distúrbios e permitindo uma avaliação de impactos ecológicos de estratégias de manejo e conservação, podendo ser boas indicadoras ecológicas da saúde dos ecossistemas.

RAMOS (2000), em um de seus estudos, relata uma boa relação entre abundância e riqueza de espécies de insetos com abundância e estrutura da vegetação. Mas as borboletas frugívoras se mostram melhores indicadoras para gradientes ambientais (BOUYER et al., 2007) e para fragmentação da paisagem (UEHARA-PRADO et al., 2007). Também estão no "ranking" para espécies indicadoras, espécies guarda-chuva ou espécies bandeira (NEW, 1997).

As borboletas estão entre alguns dos taxa mais usados com sucesso como bioindicadores, por exibirem suas exuberantes colorações, serem insetos grandes e possuírem ciclo de vida curto, estando hoje entre as melhores "bandeiras" para conservação e para monitoramento ambiental (FREITAS et al., 2003).

Além disso, têm sido muito estudadas por vários autores que avaliam distribuição, abundância e riqueza em ambientes com diferentes graus de perturbação, o que reforça seu papel de indicadoras biológicas (BROWN E FREITAS, 2000, 2003; DEVRIES , 
1997; DEVRIES \& WALLA, 2001; UEHARA-PRADO, 2003; UEHARA-PRADO et al., 2004, 2005 e 2007, LEWINSOHN et al., 2005; THOMAS, 2005; RAMOS, 2000; SAWCHIK et al., 2005, BOUYER et al., 2007).

UEHARA-PRADO et al., (2009) estudando diferentes grupos de artrópodes (Oedemeridae, Staphylinidae, Araneae, Scarabaeidae, grupo de Coleoptera epigéicas, Carabidae, Isopoda, Borboletas frugívoras (Nymphalidae), Opiliones e Amphipoda) concluíram que a composição da comunidade de borboletas frugívoras e coleópteros epigéicos foram considerados como os melhores indicadores em categorias taxonômicas maiores, discriminando o local perturbado do não perturbados, e atuando como representantes dos demais grupos de artrópodes.

A composição de espécies da comunidade de borboletas difere com a composição e estrutura da vegetação, sendo que algumas espécies de plantas são hospedeiras específicas para fases juvenis de borboletas, o que determina a sua distribuição e abundância. Outras são recursos essenciais para sobrevivência e reprodução das adultas. Deste modo, a presença de algumas plantas pode favorecer a comunidade de borboletas, comprovando uma importante relação entre borboleta e planta, fazendo destas boas indicadoras de diferentes habitat. (SAWCHIK et al., 2005)

Ambientes heterogêneos são os responsáveis pela grande diversidade da fauna, principalmente os insetos herbívoros. A heterogeneidade do habitat, perturbação e a conectividade de ambientes geralmente estão positivamente relacionadas à diversidade de borboletas.

Assim, a avaliação qualitativa do ambiente se faz importante, pois além da composição arbórea, a presença de herbáceas e arbustivas no sub-bosque é de extrema importância, pois destas muitas são plantas hospedeiras para várias borboletas nas fases juvenis (DEVRIES, 1987).

Em áreas em processo de restauração, a presença de borboletas frugívoras pode ser um indicativo de qualidade de hábitat, tanto quanto ao ambiente físico e biótico, bem como da existência de recursos alimentares para os mesmos e do restabelecimento de uma rede mais complexa de interações. Deste modo, elas se tornam um interessante grupo indicador (BROWN, 1997), e têm sido sugeridas como ideal para o monitoramento ambiental (FREITAS et al., 2003). 
O monitoramento avalia não somente como as espécies são afetadas pelas alterações ambientais, mais também como agentes que modificam ou se contrapõem a tais mudanças, como por exemplo, o declínio da diversidade de espécies especialistas, aumento da abundância de outros taxas, diminuição da eficácia na dispersão de sementes entre outros (LEWINSOHN et al., 2005 e FREITAS et al., 2006), porém sendo estudos de mais longo prazo ou contínuos. 


\section{MATERIAL E MÉTODOS}

\section{1 Área de estudo}

O estudo foi realizado no município de Botucatu - SP (Figura 01), com altitude média variando entre 500 a $800 \mathrm{~m}$, compreendendo duas províncias geomorfológicas: cuestas basálticas e depressão periférica, nas áreas de reflorestamento misto com espécies nativas, localizadas nas fazendas experimentais Edgárdia e Lageado do campus da Universidade Estadual Paulista (UNESP). A região situa-se entre as coordenadas $22^{\circ} 51^{\prime} \mathrm{S}$ e 48²6’W. O clima predominante é Cfa, com 1494,2 $\mathrm{mm}$ de precipitação média anual, distribuída principalmente entre os meses de outubro a março e temperatura média anual de $20,5{ }^{\circ} \mathrm{C}$, variando de $23,2{ }^{\circ} \mathrm{C}$ (janeiro) a $17,1{ }^{\circ} \mathrm{C}$ (julho). A vegetação original é classificada como Floresta Tropical Estacional Semidecidual (IBGE, 1992; MARTINS, 2009).

Este trabalho abrangeu o estudo de fragmentos, pastagens e áreas de restauração. Foram estudados três diferentes fragmentos florestais (1, 2 e 3), como áreas de referencia; três áreas de pastagem (1, 2 e 3), aqui usadas como padrão de áreas com alto índice de degradação, e três diferentes áreas em processos de restauração, alvo deste trabalho. Cada 
conjunto de uma área de fragmento, pastagem e restauração compõe um sítio de estudo, num total de três (sítios 1, 2 e 3, Figura 2).

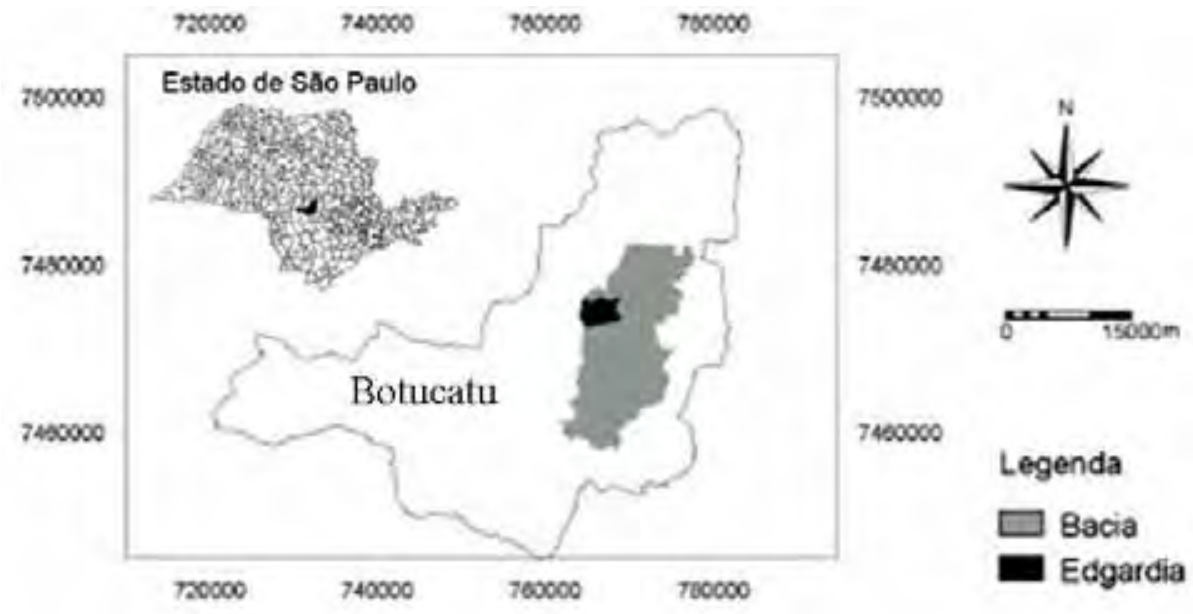

Figura 1 Limites do município de Botucatu-SP, limites da bacia hidrográfica do rio Capivari e limites da fazenda Edgárdia.

As áreas de reflorestamento foram instaladas entre 1997 e 1998, como um experimento em blocos ao acaso com cinco tratamentos e três repetições, em cada um dos três sítios. As parcelas têm uma área de 0,25 ha, totalizando uma área experimental de 3,75 ha por sítio. Os tratamentos constituem-se de quatro diferentes modelos de consorciação de espécies florestais e mais um tratamento controle, onde não foi efetuado o plantio. Os tratamentos são descritos em detalhes em ENGEL \& PARROTA (2000). Neste trabalho, os diferentes modelos de plantios foram considerados no seu todo para efeito de amostragem das borboletas, uma vez que não seria possível separar o efeito de cada tratamento para o objetivo deste trabalho.

Em cada um dos sítios estudados foram então considerados três tratamentos: a área em restauração (RES), a mata nativa (FRAG) e a pastagem (PAS), (Figura 02), onde:

- Sítio 1: está inserido dentro da Fazenda Experimental Lageado, localiza-se em uma mancha de solo do tipo Nitossolo Vermelho (NV), de ótima fertilidade e textura argilosa (EMBRAPA, 1999), relevo ondulado, com tendência a compactação, próximo ao Ribeirão Lavapés, circundado por áreas agrícolas e fragmentos de mata ciliar, localizado aproximadamente a $750 \mathrm{~m}$ de altitude. $\mathrm{O}$ fragmento de mata nativa deste sítio tem cerca de 50 
ha, este fragmento passou por etapas de produção de café até a década de 60 e para feijão entre as décadas de 70 e 80 e a partir da década de 90 foi utilizado para pastagem (LEITÃO-LIMA, 2002). A área de restauração deste sítio foi instalada próximo ao fragmento em uma área de pasto dominada por capim napier (Pennisetum purpureum) abandonado. A pastagem utilizada como tratamento desta pesquisa situa-se na margem oposta do Rio Lavapés próximo do fragmento, é composta por braquiária e ocupada por criação de gado e parte do ano para eqüinos.

- $\quad$ Sítio 2: está inserido na Fazenda Experimental Edgardia, situa-se em uma mancha de solo Argissolo Vermelho-Amarelo (AVA), álico, textura areia franca, relevo suave ondulado a ondulado, de fertilidade mais baixa e maior acidez, localizado na encosta de cuesta basáltica a $574 \mathrm{~m}$ de altitude, grande parte desta área foi primeiramente, entre as décadas de 20 e 70, utilizada como pastagem e depois como pomar de frutas cítricas, que hoje se encontra abandonado (LEITÃO-LIMA, 2002). O fragmento deste sítio encontra-se em bom estado de conservação, com cerca de 300 ha (NOGUEIRA JUNIOR., 2000) sendo um ambiente mais heterogêneo, com mais espécies e, presença das espécies que ocorrem em florestas estacionais maduras, tendo sofrido extrações seletivas de madeira até há cerca de 2530 anos atrás (CASSOLA, 2008). A matriz é composta por pasto sujo, com presença de espécies arbustiva e criação de cavalos, onde foram instaladas a área de restauração e a unidade amostral da pastagem.

- Sítio 3: está inserido também na Fazenda Experimental Edgárdia, localizado em um Latossolo vermelho-amarelo (LVA), álico, arenoso, de relevo plano a suave, a uma altitude de aproximadamente 540 m.(NOGUEIRA JUNIOR., 2000). Solo de baixa fertilidade, ácido e lixiviado, parte desta área foi utilizado para plantios de manga e nós pecã nas décadas de 60 a 80, e nos últimos anos para pastoreio (LEITÃO-LIMA, 2002). O fragmento, com aproximadamente 53 há, é composto por uma mata secundária, dominada por espécies comuns na fase sucessional precoce, muitas clareiras e colonização por trepadeiras, maior números de indivíduos no sub-bosque, porém com menor riqueza de espécie (CASSOLA, 2008), degradado pelo fogo e sofreu extração de madeira. A pastagem é uma área de braquiária sem criação de animal. Área com alto índice de incêndios. 


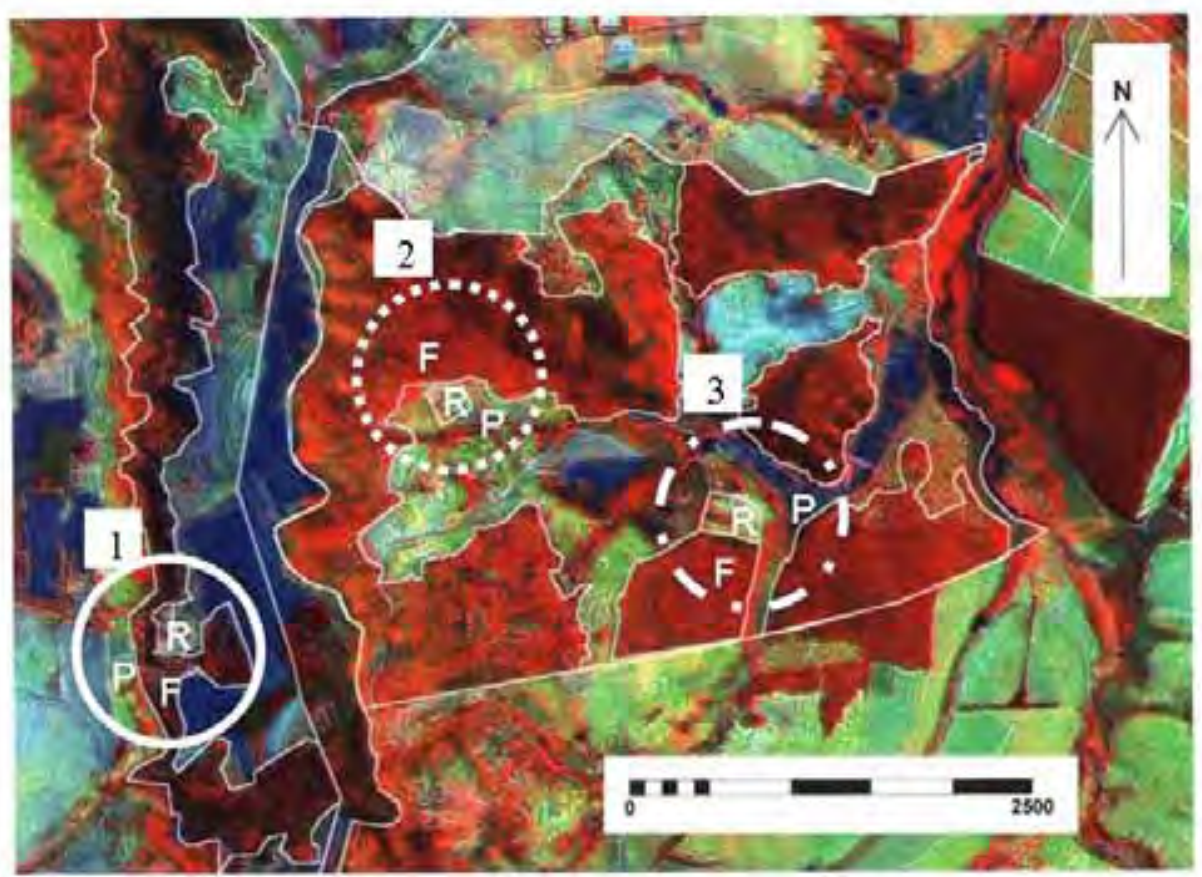

Figura 2 Imagem de satélite das Fazendas Experimentais Lageado e Edgárdia com a localização respectivamente dos sítios 1 (círculo de linha contínua); 2 ( círculo de linha pontilhada) e 3 (círculo de linha tracejada), na região de Botucatu-SP. Os fragmentos estão representados pelas letras $\mathrm{F}$, as áreas em restauração pelas letras $\mathrm{R}$ e as pastagens pelas letras P.

\subsubsection{Preparação das unidades amostrais.}

Cada armadilha foi considerada uma sub-amostra, para minimizar o efeito da posição da armadilha e da atratividade das iscas, sendo que cada unidade amostral foi composta por cindo sub-amostras (armadilhas), dispostas em transectos lineares a uma altura que variou de 1,80 a 2,20m, com distância entre elas de no mínimo 20m (DEVRIES \& WALLA, 2001), estando a pelo menos a 50m da borda, no caso dos fragmentos e nas áreas de restauração e $50 \mathrm{~m}$ distantes de qualquer outra vegetação para as pastagens.

Nos ambientes de mata (fragmentos florestais) e reflorestamento misto com nativas, as armadilhas foram amarradas nas próprias árvores existentes. Nas áreas abertas (pastagem), houve a necessidade da instalação de suportes de madeira para apoio destas armadilhas (Figura 03) e de se instalar cercas de arame farpado no entorno das unidades amostrais para proteção das armadilhas contra o gado (Figura 04). 


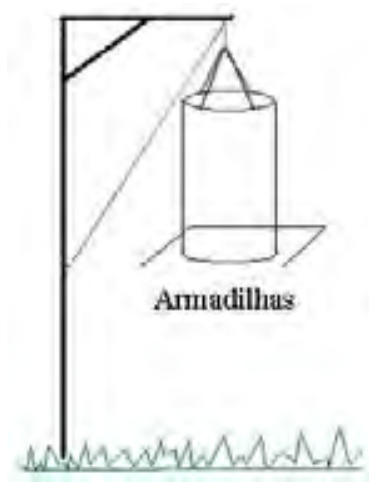

Figura 3. Esquema do suporte que sustenta as armadilhas instaladas no pasto das unidades amostrais das áreas A e B nos tratamentos de áreas abertas.

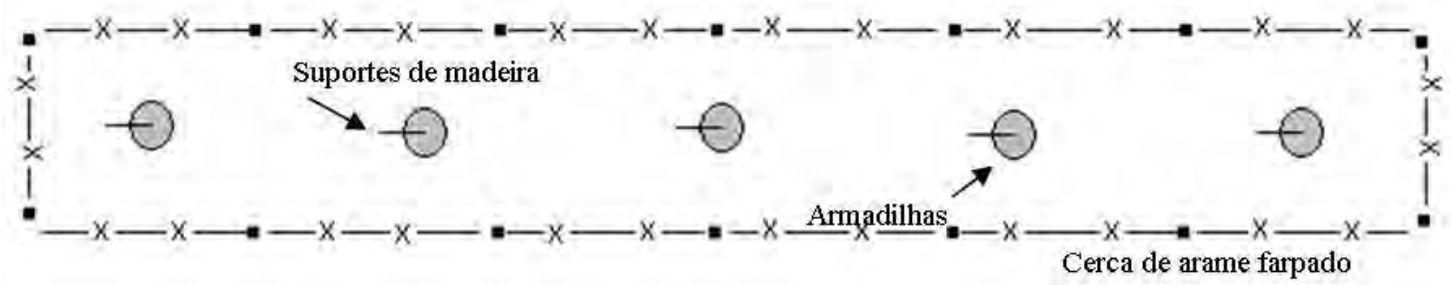

Figura 4. Esquema da disposição das armadilhas atrativas na pastagem juntamente com a cerca de arame farpado construída ao redor de cada unidade amostral.

\subsection{Amostragem das borboletas}

As coletas dos indivíduos foram feitas com armadilhas de atração, seguindo o modelo de SHUEY (1997), que visa é capaz de otimizar a captura e a retenção dos indivíduos e maximizar a sua durabilidade em campo, já que estas ficam de 6 meses a 2 anos no campo. A isca atrativa utilizada foi banana com caldo de cana fermentados por 48 horas (UEHARA-PRADO, 2003). Todas as iscas foram preparadas com banana do tipo nanica e caldo de cana processado no dia e depois de prontas repousadas em condições frescas e sombreadas até o momento de uso, para não haver o risco de fermentação diferenciada das iscas preparadas em diferentes dias.

Seguindo o protocolo de amostragem citado por UEHARA-PRADO et al. (2004), o estudo foi feito utilizando uma unidade amostral em cada tratamento (restauração, fragmento e pastagem) de cada sítio avaliado. As armadilhas de cada sítio foram 
revisadas a cada 48 horas. Em cada visita, as iscas foram substituídas para manter a atratividade e sua homogeneidade. As coletas dos lepidópteros foram feitas de novembro de 2008 a maio de 2009, período mais favorável à captura de borboletas frugívoras (BROWN, 1972).

Os indivíduos capturados e identificados em campo foram marcados numericamente, sendo registradas todas as informações de suas características individuais e liberados no mesmo local de captura. Já os indivíduos não identificados foram coletados e devidamente acondicionados em envelopes entomológicos, depois levados ao laboratório onde eram identificados com auxílio do Guia das Borboletas Frugívoras da Reserva Estadual do Morro Grande e região de Caucaia do Alto Cotia (SP) (UEHARA-PRADO et al., 2004), além de D'ABRERA (1987a, 1987b e 1988). Espécimes não identificados foram levados à professores e pesquisadores especialistas da Universidade de Campinas/Unicamp para sua identificação.

Todos os indivíduos foram registrados fotograficamente, sendo montada uma coleção fotográfica de referência com os indivíduos capturados, com a intenção de eliminar a necessidade de sacrificar aqueles indivíduos já identificados, para cada nova coleta.

Foi feita uma amostragem com média de 10 dias de coleta por mês, onde se coletou 7 meses consecutivos, totalizando um esforço de 740 horas amostradas, ou 33.300 armadilhas/hora de amostragem, considerando 10 horas ativas por armadilha, por dia de amostragem, entre os meses de novembro de 2008 a maio de 2009.

\subsection{Análise da estrutura da vegetação}

A densidade de herbáceas; porcentagem de cobertura de copas, altura do dossel, densidade de vegetação de 0-3m altura e área basal da vegetação foram estimadas para cada sítio (1, 2 e 3 ) e em cada tratamento (fragmentos, áreas em restauração e pastagens), em duas épocas do ano (agosto/2008 e abril/2009).

Para a estimativa da densidade de vegetação de 0-3m altura, foi utilizada uma vara de $3 \mathrm{~m}$ pintada de $10 \mathrm{~cm}$ em $10 \mathrm{~cm}$ (vermelho e branco), onde foi contado o número de seções de $10 \mathrm{~cm}$ (vermelhos) que foram visíveis a uma distância de $15 \mathrm{~m}$ ao longo 
dos transectos, com leituras tomadas próximo à cada armadilha e feito um calculo de porcentagem que esta vegetação ocupava do sub-bosque..

A cobertura herbácea foi amostrada em 5 pontos distantes no entorno de cada armadilha em até 10 metros, com o uso de uma moldura de madeira de $0,5 \mathrm{~m} \times 0,5 \mathrm{~m}$ preenchida com plástico transparente quadriculado, onde foi contada a porcentagem de quadrados completos por vegetação herbácea (Figura 5) (MUELLER-DOMBOIS \& ELLEMBERG, 1974) . Nos mesmos pontos em que se avaliou a densidade de herbáceas foi estimada a densidade de cobertura em porcentagem, com o uso do Densiômetro Esférico de Copas (NEWTON, 2007).

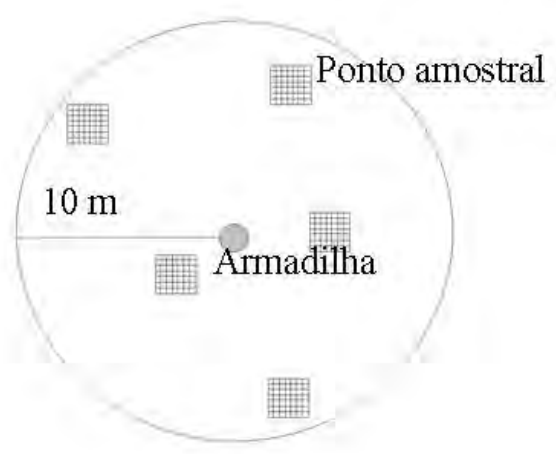

Figura 5 Esquema dos pontos amostrais ao redor de cada armadilha em cada unidade amostral para densidade de copa e densidade de herbáceas coletadas nos três habitats estudados.

A altura do dossel foi estimada a cada $10 \mathrm{~m}$ ao longo dos transectos das unidades amostrais com auxílio de uma vara de $6 \mathrm{~m}$, calculando-se uma média de dois pontos observados, resultando em um valor por armadilha. A área basal da vegetação de cada habitat foi estimada usando-se o método de Bitterlich (NEWTON, 2007), utilizando-se o fator 2, com visualizações nos pontos de cada armadilha dando um giro de $360^{\circ}$, até $10 \mathrm{~m}$ de raio no entorno de cada armadilha. (Figura 6). 


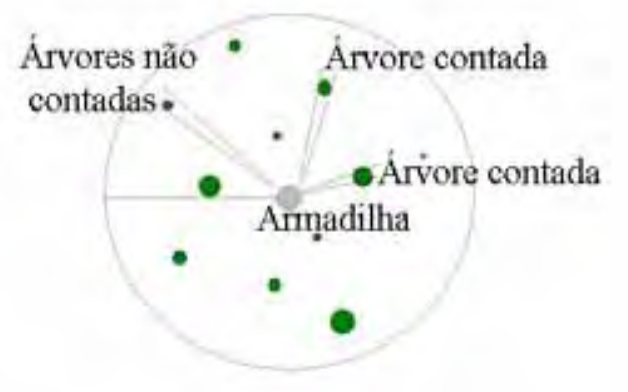

Figura 6 Representação da amostragem da área basal feita com o método de Bitterlich para cada armadilha dentro de cada unidade amostral estudado dentro de cada tratamento dos três sistemas estudados.

\subsection{Análise dos dados}

Foram feitas as análises de riqueza observada e abundância total e por espécie, e calculados os índices de diversidade de Shannon-Wiener $\left(H^{\prime}=-\sum p_{i} \ln p_{i}\right)$, e o índice alfa de Fisher para cada tratamento, bem como a equidade de Pielou (J) (Magurran, 2004). Foram feitas as análises de composição e distribuição das espécies de borboletas para cada tratamento e em cada sítio.

As comparações de riqueza entre os tratamentos foram feitas com base nas curvas de rarefação (método de "bootstrap").Todos os índices foram calculados pelo programa PAST (HAMMER et. al., 2001), bem como as comparações dos índices em pares de unidades amostrais (tratamentos).

Os padrões de dominância entre as espécies em cada sítio e cada tratamento foram comparadas através de curvas de abundância "ranqueada" de espécies, utilizando-se o diagrama de Whittaker (MAGURRAN, 2004).

Os estudos de similaridade entre as comunidades nos diferentes tratamentos foram feitos através da análise de agrupamento pelo método de grupo pareado (média aritmética UPGMA) e distâncias interespecíficas de Bray-Curtis, em combinação com análise de correspondência (CA), utilizando-se o software PAST (HAMMER et. al., 2001). A relação entre as variáveis de qualidade do habitat e a abundância e riqueza da comunidade de borboletas foi avaliada através de análise de regressão múltipla do tipo "stepwise" utilizandose o programa Statistica 6. 


\section{RESULTADOS E DISCUSSÃO:}

\subsection{A comunidade de borboletas}

Foram capturados 978 indivíduos de 48 espécies de borboletas da guilda das borboletas frugívoras da família Nymphalidae, dividida entre seis subfamílias: Biblidinae, Satyrinae Charaxinae, Brassolinae, Nymphalinae e Morphinae. Resultado satisfatório, representando $68,5 \%$ das espécies amostradas por UEHARA-PRADO et al.(2005), que encontraram dentre as mesmas 6 subfamílias, 70 espécies em 1810 indivíduos, estudando áreas contínuas e fragmentos de mata atlântica no Planalto Atlântico Paulista, para um mesmo esforço amostral.

A quantidade de indivíduos capturados foi diferente entre os meses de coletas, sendo que os meses de maiores abundâncias foram os meses de menor precipitação (figura 7), estando de acordo com a afirmação de BROWN (1992). Este autor sugere que, apesar dos melhores meses para coletas desta guilda ser entre os meses de novembro a maio, pois as eclosões das pupas se iniciam com as chuvas, afirma que para as próximas gerações, muitas lagartas de borboletas são parasitadas por fungos,com aumento da temperatura e das 
chuvas, levando estas à morte, diminuindo então o número de indivíduos adultos de maio a novembro.

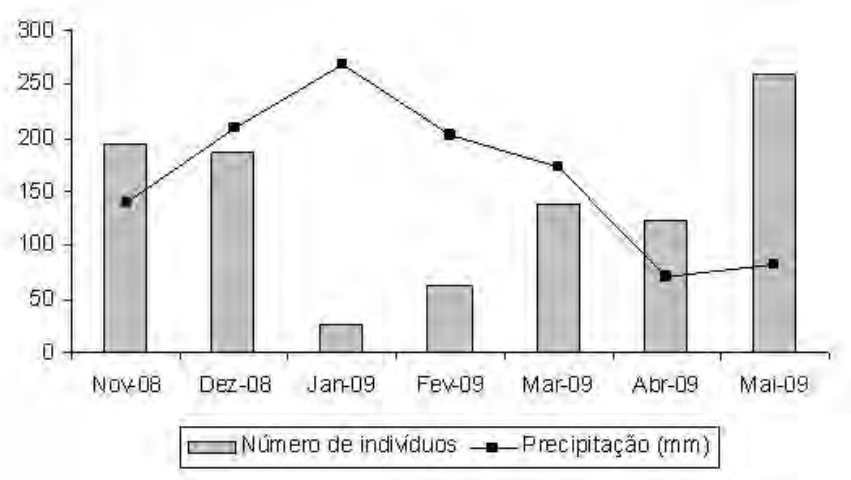

Figura 7 Relação temporal da abundância das espécies de borboletas frúgivoras com a precipitação (Balanço hídrico Normal 1971-2008 por MARTINS, 2009) para os meses de novembro de 2008 a maio de 2009 nas fazendas experimentais do Lageado e Edgárdia (SP).

\subsubsection{Abundância, Riqueza e Diversidade de espécies entre os tratamentos}

A área em processo de restauração mostrou o maior número de indivíduos observados $(\mathrm{N}=554)$, representando mais de 50\% do total dos indivíduos coletados ( $\mathrm{N}=978)$ na amostragem. A riqueza observada foi maior para as áreas em processo de restauração e menor para as áreas de pastagens, onde a pastagem não atingiu 50\% das espécies coletadas no total (figura 8).
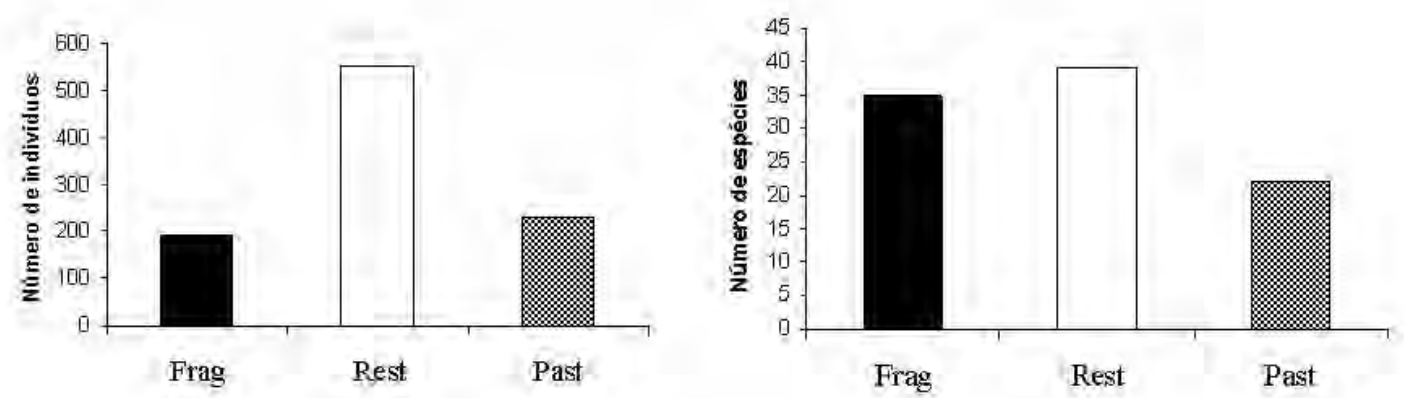

Figura 8 Abundância e Riqueza total das espécies de borboletas frugívoras em cada tratamento coletadas, no período de coleta de nov/2008 a mai/2009. Frag: fragmento; Rest: restauração; Past: pastagem. 
Avaliando-se os três tratamentos (fragmento, pasto e restauração) dentro cada sítio (1, 2 e 3) (figura 9), pode-se observar que o fragmento 2 apresentou o menor número de indivíduo coletados e menor riqueza de espécies capturadas entre os outros dois fragmentos (Frag 1 e Frag 3). Isso ocorreu provavelmente devido ao esforço amostral não ter sido suficiente para representar toda a riqueza deste fragmento, talvez por este ser um fragmento grande (300 ha) e o maior dentre os três fragmentos estudados.

O sítio 1 apresentou no geral, resultados diferenciados das demais áreas estudadas (2 e 3). A pastagem do sítio 1 teve o menor número de indivíduos e a menor riqueza de espécies entre todas as outras (Past 2 e Past 3) (figura 9), o que pode ser explicado pelo fato de ser a única pastagem ativa, enquanto as outras pastagens são áreas de pastos abandonados e/ou com baixa intensidade de uso por animais de pastoreio. Também a área em processo de restauração 1 (Rest 1) apresentou a menor riqueza observada ( $S=7$ ) (figura 9), comparada as outras restaurações (Rest 2 e 3), ou mesmo a qualquer outro tratamento avaliado, porém mantendo a média alta de numero de indivíduos coletados $(\mathrm{N}=189)$ equivalente com as demais áreas de restauração estudadas (Rest 2 e 3). O sítio 1 é aquele mais antropizado entre os três, com menor quantidade e qualidade de fragmentos de vegetação nativa , sendo dominado por unidades agrícolas e pastagens, o que pode ter influído na menor riqueza de espécies em todos os tratamentos desta área.

A soma das abundâncias das duas espécies mais abundantes deste tratamento (Rest1) representou $88 \%$ do total de indivíduos e as outras 5 espécies representaram apenas $12 \%$ do total de indivíduos coletados neste tratamento. Fato este, que permitiu reforçar a idéia de que há a possibilidade da influência da vizinhança nas áreas restauradas, tanto da pastagem ativa ao redor desta área restaurada como das próprias áreas agrícolas da Fazenda, Experimental Lageado e estradas com alto índice de movimentação por tratores, carros e pedestres, onde está inserido este tratamento (Rest 1). 


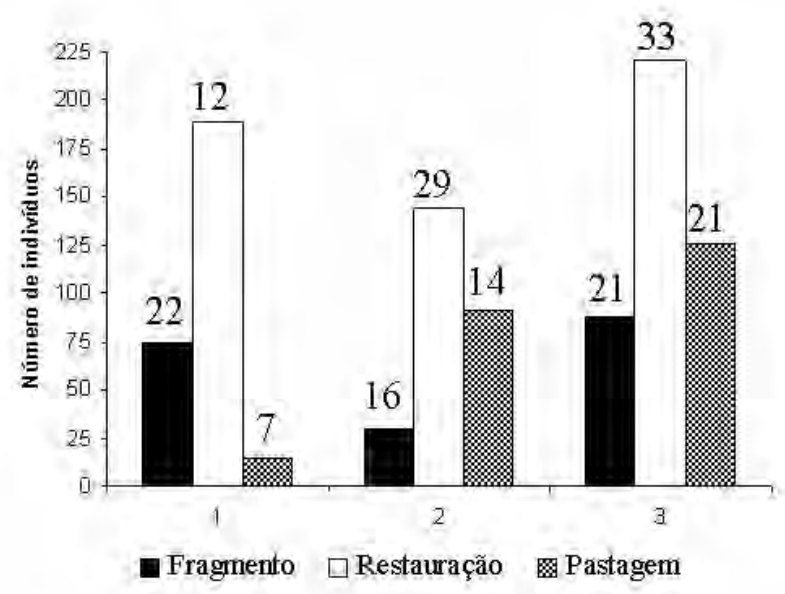

Figura 9 Abundância e riqueza das espécies de borboletas frugívoras em cada tratamento dentro de cada sítio (1, 2 e 3 ) entre o período de novembro/2008 a maio/2009, onde os números acima de cada barra representam a riqueza observada para cada ambiente.

Mesmo as áreas em processo em restauração tendo apresentado o maiores valores para abundância e riqueza observada, as curvas de rarefação (Figura.10) mostram que os fragmentos detêm a maior riqueza esperada, seguida das áreas em restauração, ambos maiores que as pastagens. Isso permite afirmar que os fragmentos são ambientes mais ricos em espécies de borboletas, e que talvez o esforço amostral não tenha sido suficiente para amostrar a riqueza de espécies destes remanescentes florestais. Já as áreas em restauração e pastagens parecem ter sido suficientemente amostradas, com as áreas restauradas possuindo diversidade de borboletas frugívoras mais próxima aos fragmentos e diferentes das pastagens.

DAYLY E EHRLICH (1995) afirmam que ambientes perturbados podem sofrer perda ou modificação dos habitats e dos recursos de uma guilda, o que leva a diminuição de espécies e da abundância, tornando difícil a avaliação da biodiversidade pela análise da abundância e riqueza de espécies. Muitos questionamentos surgem com relação à avaliação apenas da abundância e presença de espécies, sendo que outros autores afirmam que em ambientes perturbados a abundância e o número de espécies podem ser superiores, o que podem estar ligado a fatores específicos de cada ambiente (DEVRIES et al., 1997). 


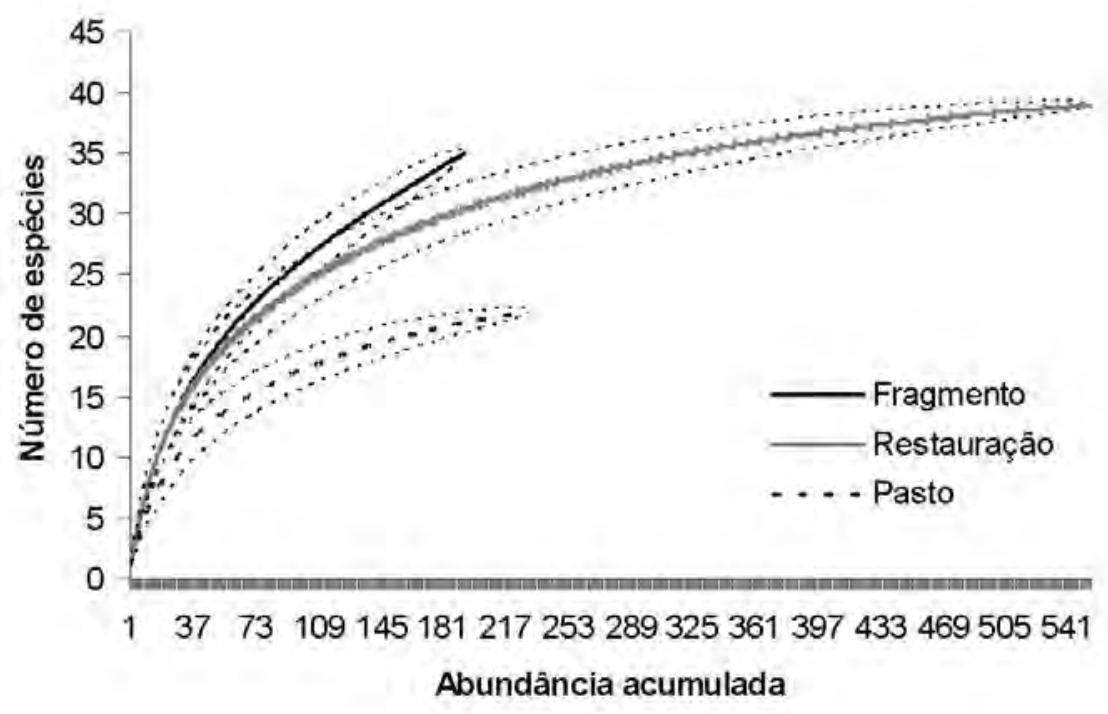

Figura 10 Curva de rarefação (método de "bootstrap") da comunidade de borboletas frugívoras para os tratamentos fragmentos, restauração e pasto. As linhas pontilhadas representam $95 \%$ de intervalo de confiança para as curvas.

Comprando-se os três tratamentos quanto aos índices de diversidade, notas-se que as áreas de pastagem tiveram uma menor heterogeneidade de espécies (tanto pelo índice H' quanto pelo alfa de Fisher) e menor eqüidade (J) do que as áreas em restauração e pastagem, conforme Tabela 3. Por outro lado, as áreas em restauração e os fragmentos não diferiram entre si a 5\% de probabilidade quanto aos índices de diversidade e eqüidade (Tabela $1)$.

Tabela 1 Número de espécies, abundância e índices de diversidade para do levantamento de borboletas frugívoras realizado em cada tratamento durante as coletas de Nov/2008 a maio/2009.

\begin{tabular}{llll}
\hline Índices & Fragmento & Restauração & Pasto \\
\hline Espécies & 35 & 39 & 22 \\
Indivíduos & 193 & 554 & 231 \\
Shannon H' & $2.842 \mathrm{a}$ & $2.905 \mathrm{a}$ & $2.098 \mathrm{~b}$ \\
Equidade $\mathrm{J}$ & $0.7993 \mathrm{a}$ & $0.793 \mathrm{a}$ & $0.6788 \mathrm{~b}$ \\
Alfa de Fisher & $12.5 \mathrm{a}$ & $9.569 \mathrm{a}$ & $5.979 \mathrm{~b}$ \\
\hline \multicolumn{2}{l}{ Os valores seguidos de letras iguais não diferiram estatisticamente, $(\mathrm{p}<0,05)}$.
\end{tabular}


O diagrama de Whittaker (MAGURRAN, 2004) mostra a diferença de heterogeneidade entre os ambientes e a maneira como a abundância se distribui entre as espécies, apontando uma grande dominância de poucas espécies para todos os tratamentos, sendo isso mais acentuado nas pastagens, o que significa alta dominância e baixa eqüidade deste ambiente, ao passo que na restauração e fragmentos há uma maior heterogeneidade da comunidade (Figura 11).

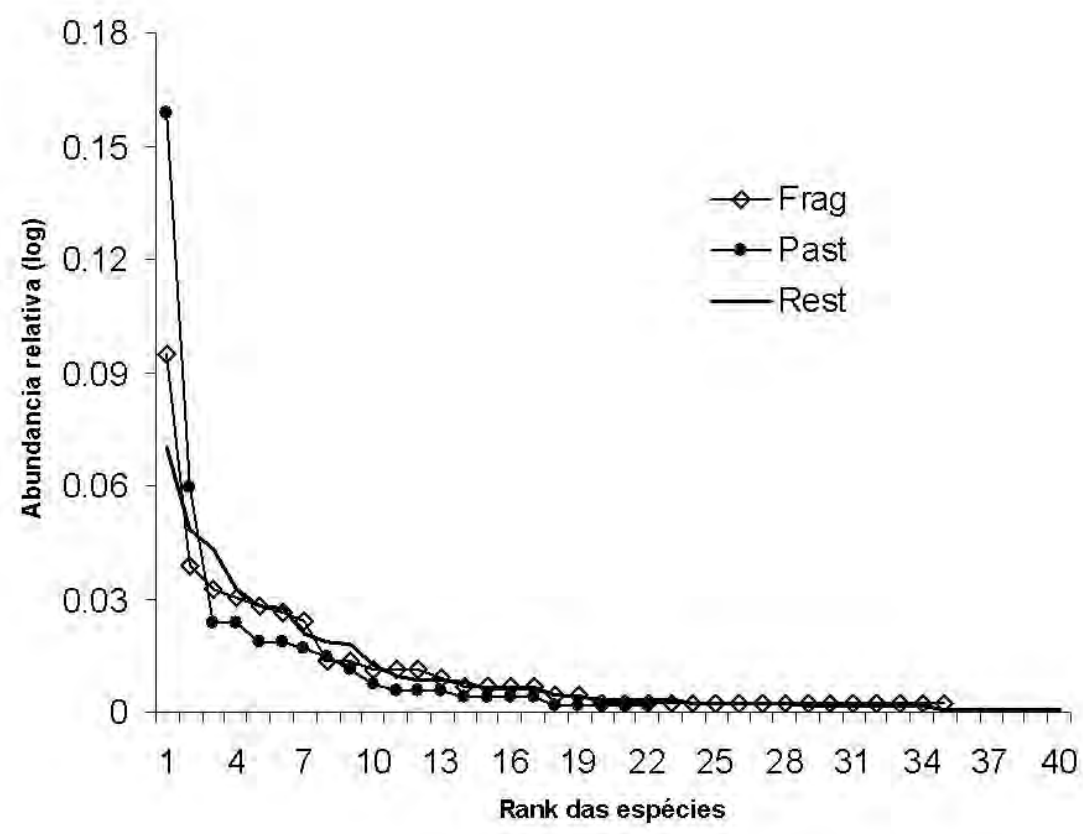

Figura 11 Curvas de distribuição ranqueada de abundâncias por tratamento (Diagrama de Whittaker), onde o eixo Y mostra logaritmo da abundância relativa e o eixo X mostra o "ranking" das espécies, ordenadas da mais abundante para a menos abundante, para os três tratamentos estudados, no período de novembro /2008 a maio/2009.

\subsubsection{Composição de espécies de borboletas frugívoras}

Dentre as 48 espécies distribuídas dentro das seis subfamílias, a maioria das espécies estava representada pela subfamília Biblidinae que com 17 espécies representou 35\% do total e a subfamília Satyrinae com 14 espécies representou 29\%, sendo assim as subfamílias Charaxinae, Brassolinae, Nymphalinae e Morphinae juntas, representaram $36 \%$ das espécies coletadas (Tabela 2 ). 
A subfamília mais abundante nos fragmentos foi a subfamília Biblidinae seguida da Satyrinae. Na restauração a subfamília Satyrinae foi a mais abundante e em segundo foi a Biblidinae e na pastagem a subfamília mais abundante foi a Biblidinae seguida pela Charaxinae e a ausente nas pastagens foi a subfamília Morphinae (Tabela 2).

Tabela 2 Total da Abundância e Riqueza de espécies das subfamílias de borboletas frugívoras pertencentes à família Nymphalidae dos três tratamentos (fragmento, restauração e pasto) nas Fazendas experimentais Lageado e Edgárdia (SP) de novembro de 2008 a maio de 2009.

\begin{tabular}{lrrrrrrr}
\hline \multirow{2}{*}{ Subfamilia } & \multicolumn{9}{c}{ Número de indivíduos $(\mathrm{N})$} & \multicolumn{3}{c}{ Riqueza de espécies } & \multirow{2}{*}{ N Total } \\
\cline { 2 - 7 } & Frag & Rest & Pasto & Frag & Rest & Pasto & \\
\hline Biblidinae & 71 & 200 & 141 & 8 & 14 & 9 & 412 \\
Satyrinae & 54 & 234 & 6 & 13 & 10 & 3 & 294 \\
Charaxinae & 30 & 82 & 54 & 8 & 9 & 6 & 166 \\
Brassolinae & 11 & 22 & 19 & 3 & 3 & 2 & 52 \\
Nymphalinae & 21 & 15 & 11 & 2 & 2 & 2 & 47 \\
Morphinae & 6 & 1 & 0 & 1 & 1 & 0 & 7 \\
\hline \multicolumn{1}{c}{ Total } & $\mathbf{1 9 3}$ & $\mathbf{5 5 4}$ & $\mathbf{2 3 1}$ & $\mathbf{3 5}$ & $\mathbf{3 9}$ & $\mathbf{2 2}$ & $\mathbf{9 7 8}$ \\
\hline
\end{tabular}

A Tabela 3 mostra o número de indivíduos de cada espécie e a distribuição destas espécies dentro dos tratamentos estudados. Quanto à composição de espécies de cada tratamento, pode-se observar que algumas espécies não foram encontradas no fragmento, outras não foram encontradas na pastagem e outras não foram encontradas na restauração, e que há espécies que apareceram apenas em um dos três tratamentos (frag, rest e past). Podendo encontrar dentre estas, espécies que indicam alguma condição de ambiente, pois segundo alguns autores (DEVIRIES et al., 1997; BROWN \& FREITAS 2000) borboletas são sensíveis a mudanças no habitat, se mostrando indicadoras de qualidade ambiental e integridade da paisagem natural.

A espécie Callicore sorana (Figura 12) foi a mais abundante de todas as espécies $(\mathrm{N}=129)$ (Tabela 3), sendo esta a mais abundante na pastagem $(\mathrm{N}=102)$ e ausente no fragmento, dados semelhantes aos encontrados por FURLANETTI, P.R.R. (2006, dados não publicados), indicando que esta espécie seria favorecida por ambientes abertos ou de borda. Em seguida a Yphthimoides sp., com N=103 (tabela 2) apareceu em maior abundância 
na restauração 1 (Rest 1) com $\mathrm{N}=97$, dados que corroboram os encontrados por BARLOW et al., (2007), que Satyrinae são as mais abundantes em plantios de eucalipto e os de UEHARAPRADO et al., (2003), que indicaram ser a subfamília Satyrinae generalista quanto a habitats na paisagem.
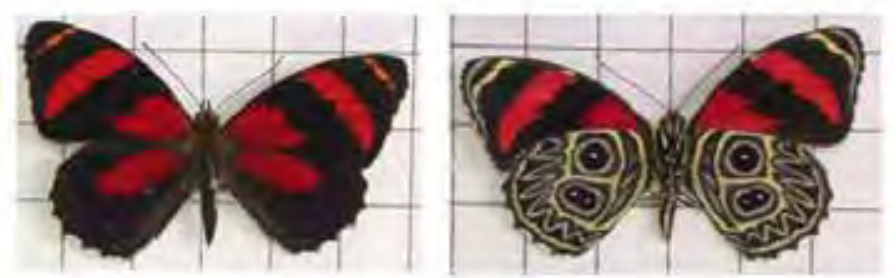

Figura 12 Foto da espécie Callicore sorana, da subfamília Biblidinae, vista da face ventral e a face dorsal consecutivamente.

Observa-se que apareceram apenas oito espécies nos fragmentos (Myscelia orsis, Catonephele acontius, Catonephele numilia, Catoblepia berecynthia, Taygetis tripunctata, Taygetis ypthima, Yphthimoides Renata, Zischkaia fumata), exclusivas deste ambiente, outras quatro espécies exclusivas da restauração (Ectima thecla, Haematera pyrame, Pyrrhogyra neaerea, Pharneuptchia pharella) e por último uma espécies que foi encontrada somente na pastagem (Biblis hyperia). Observa-se também mais espécies em comum entre restauração e fragmento (14 espécies, 29\% do total de 48 espécies) do que entre restauração e pastagem (oito espécies). Nenhuma foi comum apenas entre fragmento e pastagem. No total, treze espécies entre 48 (27\%) foram comuns aos três ambientes.

Avaliando a distribuição de abundâncias das espécies dentro de cada tratamento (fragmento, restauração e pastagem), pode-se observar tanto a composição das espécies quanto a abundância das mesmas foram diferentes.

Entre as 13 espécies mais abundantes (N>20) (Figura 13), é possível definir as espécies que caracterizam cada ambiente (fragmento, restauração e pastagem). Entre as mais abundantes, Hamadryas epinome (Biblidinae), P. phronius (Satyrinae), P. poltis (Satyrinae), C. selima (Biblidinae) e T. virgilia (Satyrinae) foram comuns entre restauração e fragmentos e ausentes na pastagem. T. virgilia foi considerada por RAMOS (2000) como indicadora de ambientes preservados na Amazônia. As espécies que estavam ausentes em fragmentos foram: Callicore sorana e Memphis appias, o que está de acordo com UEHARA- 
PRADO et al., (2003) que dizem ser M. appias (Biblidinae) favorecida pelo processo de fragmentação da paisagem.

Tabela 3 Lista de espécies de lepidópteros da família Nymphalidae coletadas em cada tratamento: fragmentos (Frag), pastagens (Past) e restauração (Rest), no período de nov/2008 a maio/2009.

\begin{tabular}{|c|c|c|c|c|c|}
\hline Subfamília & Espécie & & Frag & Pasto & Rest \\
\hline \multirow[t]{18}{*}{ Biblidinae } & Callicore sorana & Godart, 1823 & & 102 & 27 \\
\hline & Hamadryas februa & Hübner, 1823 & 15 & 10 & 68 \\
\hline & Hamadryas epinome & Felder \& Felder, 1867 & 47 & & 36 \\
\hline & Hamadryas amphinome & Linnaeus, 1767 & 1 & 10 & 24 \\
\hline & Callicore selima & Guenee, 1872 & 1 & & 16 \\
\hline & Temenis laothoe & Cramer, 1777 & & 8 & 8 \\
\hline & Hamadryas feronia & Linnaeus, 1758 & & 2 & 8 \\
\hline & Diaethria candrena & Godart, 1821 & & 4 & 1 \\
\hline & Eunica tatila & Herrich-Schäffer, 1855 & & 3 & 2 \\
\hline & Nica flavilla & Godart, 1824 & 3 & & 2 \\
\hline & Ectima thecla & Fabricius, 1796 & & & 4 \\
\hline & Callicore hydaspes & Drury, 1782 & & 1 & 2 \\
\hline & Myscelia orsis & Drury, 1782 & 2 & & \\
\hline & Biblis hyperia & Cramer, 1780 & & 1 & \\
\hline & Catonephele acontius & Linnaeus, 1771 & 1 & & \\
\hline & Catonephele numilia & Hewitson, 1852 & 1 & & \\
\hline & Haematera pyrame & Hübner, 1819 & & & 1 \\
\hline & Pyrrhogyraneaerea & Limnaeus, 1758 & & & 1 \\
\hline \multirow[t]{4}{*}{ Brassolinae } & Opsiphanes invirae & Hüner, 1818 & 6 & 13 & 10 \\
\hline & Blepolenis batea & Hübner, 1822 & & 6 & 8 \\
\hline & Eryphanis reevesi & Doubleday, 1849 & 4 & & 4 \\
\hline & Catoblepia berecynthia & Cramer, 1777 & 1 & & \\
\hline \multirow[t]{9}{*}{ Charaxinae } & Fountainea ryphea & Geyer, 1834 & 5 & 34 & 37 \\
\hline & Memphis moruus & Fabricius, 1775 & 12 & 3 & 11 \\
\hline & Memphis appias & Hübner, 1825 & & 13 & 11 \\
\hline & Archaeoprepona demophon & Linnaeus, 1758 & 5 & 1 & 5 \\
\hline & Zaretis itys & Cramer, 1777 & 1 & 2 & 6 \\
\hline & Archaeoprepona chalciope & Hübner, 1825 & 1 & 1 & 4 \\
\hline & Hypna clytemnestra & Cramer, 1777 & 3 & & 3 \\
\hline & Memphis otrere & Hübner, 1825 & 2 & & 3 \\
\hline & Archaeoprepona demophoon & Hübner, 1819 & 1 & & 2 \\
\hline Morphinae & Morpho helenor & Cramer, 1776 & 6 & & 1 \\
\hline \multirow[t]{2}{*}{ Nymphalinae } & Smyrna blonfildia & Fabricius, 1781 & 18 & 9 & 12 \\
\hline & Colubura dirce & Linnaeus, 1758 & 3 & 2 & 3 \\
\hline \multirow[t]{14}{*}{ Satyrinae } & Yphthimoides sp & & 5 & 1 & 97 \\
\hline & Taygetis laches & Fabricius, 1781 & 14 & 2 & 58 \\
\hline & Paryphthimoides phronius & Godart, 1823 & 3 & & 43 \\
\hline & Paryphthimoides poltis & Prittwitz & 13 & & 23 \\
\hline & Taygetis virgilia & Weymer 1910 & 11 & & 2 \\
\hline & Yphthimoides affinis & Hübner, 1821 & 1 & 3 & 4 \\
\hline & Moneuptychia soter & Butler, 1877 & 1 & & 3 \\
\hline & Hermeuptychia hermes & Fabricius, 1775 & 1 & & 2 \\
\hline & Praepedaliodes phanias & Hewitson, 1862 & I & & 1 \\
\hline & Pharneuptchia pharella & Butler, 1866 & & & 1 \\
\hline & Taygetis tripunctata & Fabricius, 1793 & 1 & & \\
\hline & Taygetis ypthima & Cramer, 1776 & 1 & & \\
\hline & Yphthimoides renata & Butler, 1867 & 1 & & \\
\hline & Zischkaia paccarus & Butler, 1867 & 1 & & \\
\hline Total geral & & & 193 & 231 & 554 \\
\hline
\end{tabular}


Entre restauração e pastagem as comuns foram C. sorana (Biblidinae), M. appias (Charaxinae), T. laothoe (Biblidinae), Blepolenis batea (Brassolinae) e H. feronia (Biblidinae). As espécies ausentes nas pastagens foram: H. epinome, P. phronius e P. poltis (Figura 13).

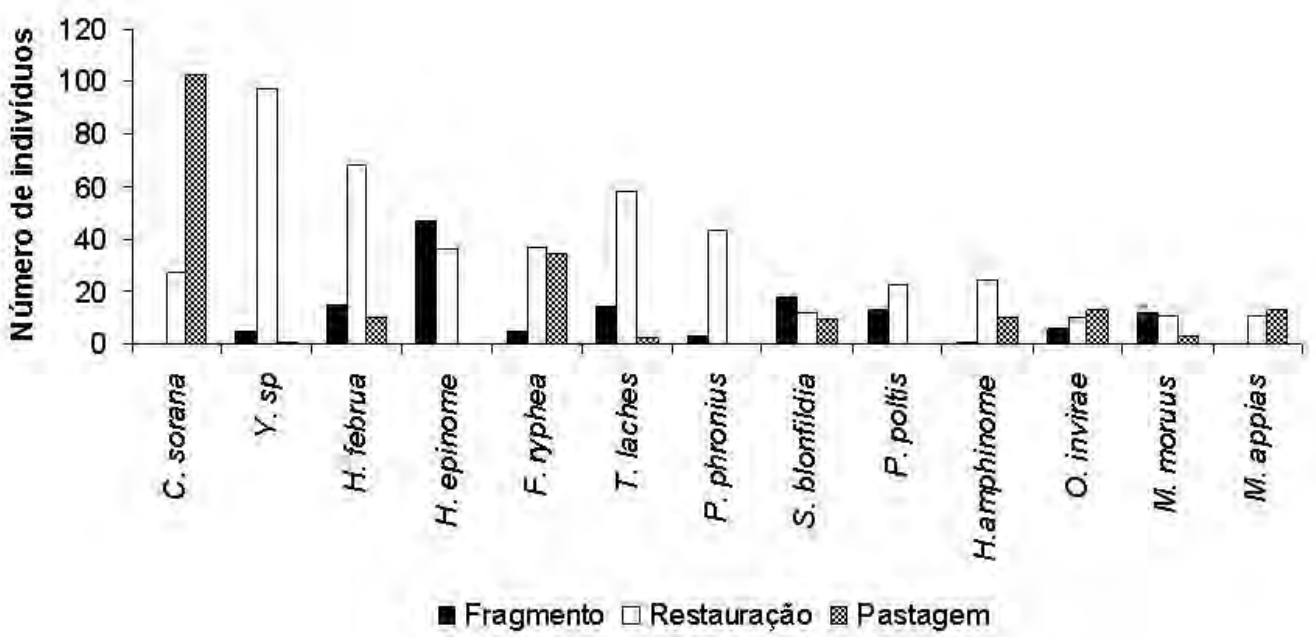

Figura 13 Número de indivíduos das 13 espécies mais abundantes ( $\mathrm{N}>20)$, para cada tratamento (restauração, fragmento e pastagem), no período de novembro/2008 a maio/2009.

Analisando as mesmas 13 espécies e sua distribuição de abundâncias em cada ambiente $(\mathrm{N}>20)$, pode se entender as diferenças entre os mesmos. Para o ambiente da pastagem pode-se observar a grande dominância de uma única espécie (C. sorana) e a desigualdade da distribuição de abundâncias entre demais, podendo dizer que este ambiente é menos heterogêneo em relação à comunidade das borboletas frugívoras (Figura 14a).

Os fragmentos apresentaram também uma espécie dominante, porém a diferença entre a primeira e a segunda mais abundante é bem menor que na pastagem: de 45 para 20 (Figura 14 b), enquanto na pastagem foi de 100 para 30 indivíduos (Figura 14 a).

Já nas áreas em restauração, observa-se uma distribuição de abundâncias das espécies mais equilibrada entre os tratamentos (Figura 14c); ou seja, maior equidade entre as espécies, indicando uma maior heterogeneidade na comunidade. 


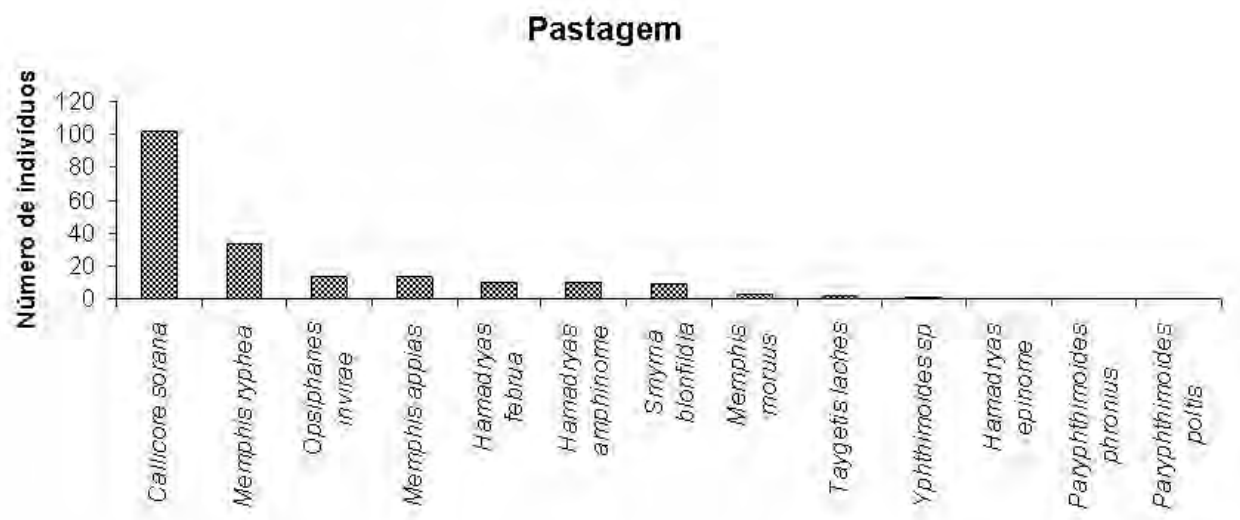

Figura 14a Ranking das 13 espécies mais abundantes $(\mathrm{N}>20)$ ordenadas da mais abundante para a menos abundante no tratamento Pastagem.

Fragmentos

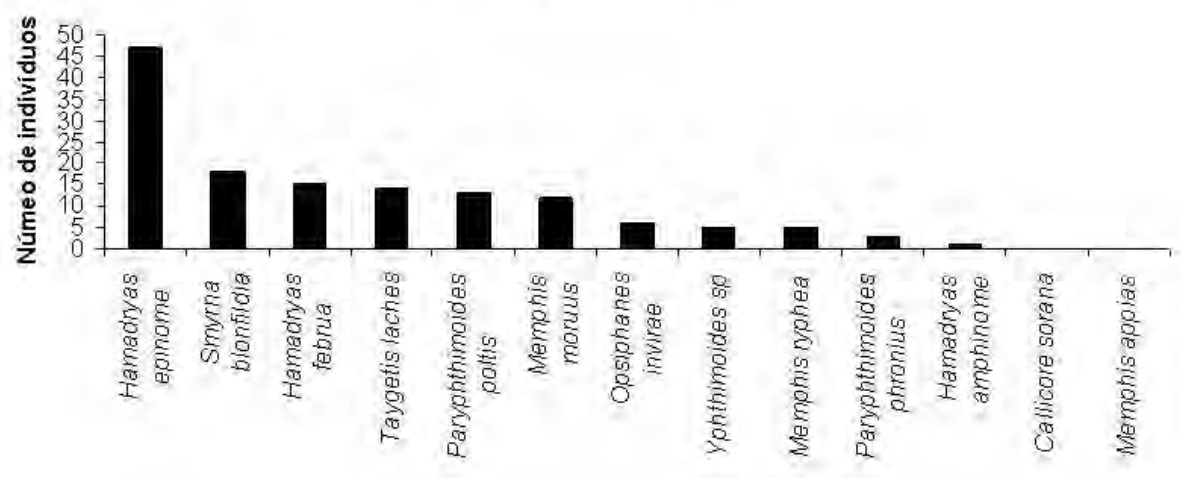

Figura 14b Ranking das 13 espécies mais abundantes ( $\mathrm{N}>20)$ ordenadas da mais abundante para a menos abundante no tratamento Fragmento.

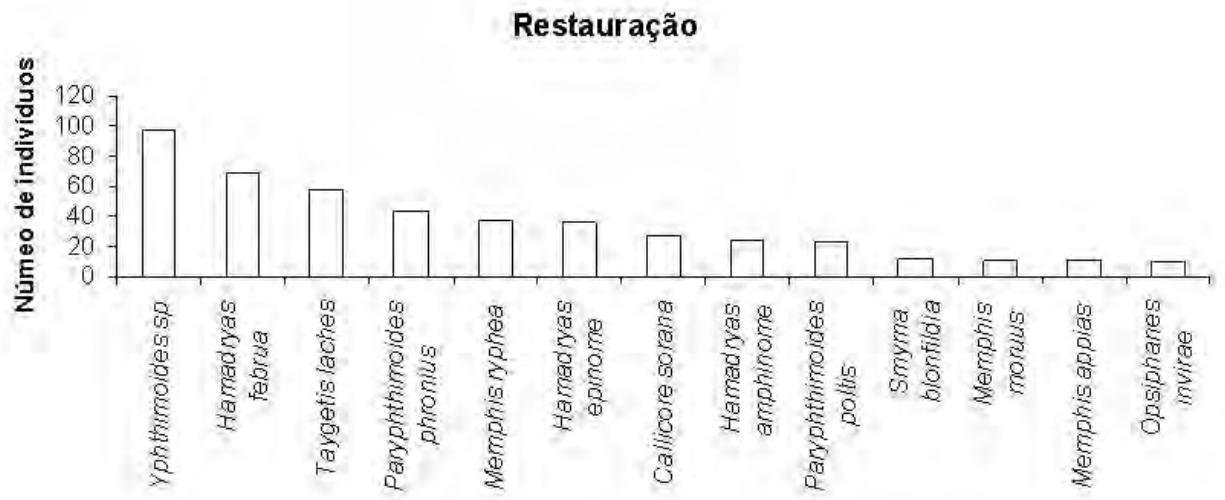

Figura 14c Ranking das 13 espécies mais abundantes ( $\mathrm{N}>20)$ ordenadas da mais abundante para a menos abundante no tratamento Restauração. 
A análise de agrupamento indicou a formação de dois grandes grupos (Figura 15), sendo o grupo A representado pelas pastagens, com similaridade muito baixa (menos de 32\%) com o segundo grupo (B), que foi formado pelos fragmentos e áreas em restauração. Esses resultados confirmam a hipótese de que as áreas em restauração seriam mais similares às áreas de fragmentos do que as de pastagens, no que se refere à comunidade de borboletas.

O grupo A segregou-se em dois sub-grupos com mais de $65 \%$ de semelhança (Figura 15), correspondendo ao grupo dos Pastos 2 e 3 e o grupo do Pasto 1. Novamente ressalta-se o fato da pastagem da área 1 ser uma pastagem ativa, mais antropizada, e portanto muito diferente dos demais sítios.

Dentro do grupo $\mathrm{B}$, as áreas de restauração 1 e Fragmentos 2 se separaram dos demais subgrupos formados, o primeiro formado pelas restaurações 2 e 3 e o outro subgrupo formado pelos fragmentos 1 e 3 . A segregação do Fragmento 2 dos demais pode ser explicada por ser este fragmento o mais bem conservado e de maior área total, o que certamente o diferencia dos demais quanto à qualidade de habitats para a guilda de borboletas frugívoras. Por outro lado, a área de Restauração 1, por estar também situada em uma paisagem mais antropizada, diferencia-se das demais áreas em restauração por receber maior contribuição de espécies características de áreas mais abertas, como é o caso de Yphthimoides sp., espécie mais generalista quanto ao habitat.. 


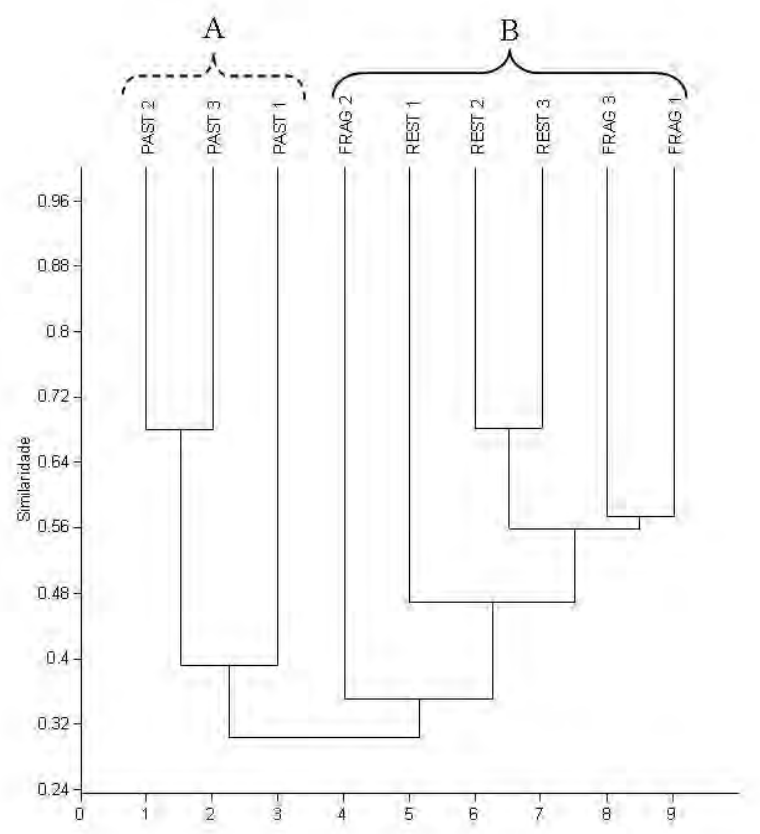

Figura 15 Análise de Cluster, por distância de Bray-Curtis, (correlação cofenética = 79,32\%), das espécies de borboletas frugívoras Nymphalidae nos tratamentos (Fragmento, restauração e pastagem) (UPGMA).

A análise de correspondência segregou em três grupos (Figura 16). As áreas de pastagens (linha tracejada) se agruparam no mesmo quadrante, mostrando aproximação entre as características da comunidade de borboletas destes ambientes. Outro grupo foi o dos fragmentos (linha contínua), que se localizaram abaixo do eixo 2 e próximos ao eixo 1, mostrando também uma semelhança maior da comunidade de borboletas.

Já o grupo formado pelas áreas em processo de restauração (linha pontilhada) mostra uma semelhança menor entre os sítios (Rest 1, 2 e 3), sendo que cada uma delas ficou separada das outras pelos dois eixos. Este padrão sugere que, embora a diversidade das áreas em restauração seja comparável à dos fragmentos, cada um dos sítios em restauração apresenta comunidades distintas, indicando trajetórias sucessionais diferentes (SUDING,E GROSS, 2006) Porem, a volta e o estabelecimento das espécies deverão ser controlados pelo regime dos distúrbios que cada área sofre no decorrer do tempo (WHITE E JENTSCH, 2004). Isso reforça também o papel deste grupo como bioindicadores de restauração. 


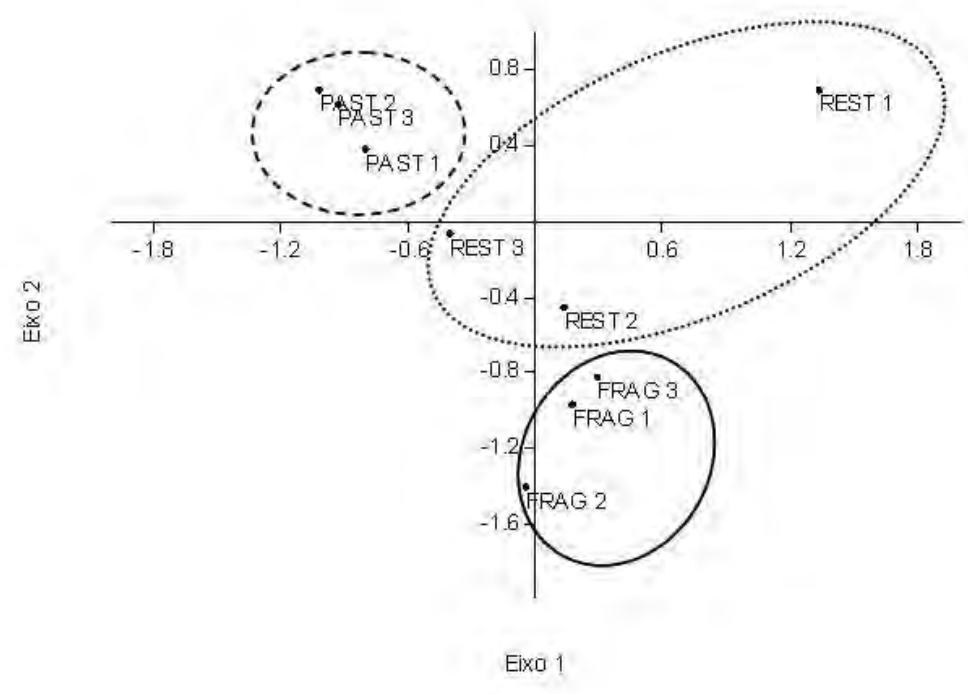

Figura 16 Análise de correspondência para a comunidade de borboletas frugívoras (com base em dados de abundância de espécies).

A restauração 3 (Rest 3 ) tem suas características mais próximas às pastagens, justamente por ser um sítio que sofreu alguns distúrbios de incêndios e invasões de gado, sendo o habitat mais aberto e com menor riqueza de espécies arbóreas. E o fragmento do sítio 2 (Frag 2) que se distanciou um pouco dos outros dois dentro do seu grupo, por este ser o fragmento de maior área e mais bem conservado entre todos.

\subsection{Qualidade do habitat e relação com a comunidade de borboletas frugívoras}

Os habitats estudados têm características estruturais intrinsecamente diferentes (Tabela 4), sendo que os fragmentos florestais (Figura 17) apresentaram maiores médias de cobertura de copas, densidade de vegetação, área basal e altura dominante, e menores valores de cobertura de herbáceas, seguidos pelas áreas em restauração (Figura 18) e pastagens (Figura 19)

A área em processo de restauração (figura 18) apresentou médias intermediárias para todas as variáveis avaliadas quando comparados com as médias dos fragmentos e pastagens, exceto para densidade de gramíneas. Para a densidade de herbáceas a restauração obteve média intermediária, porém com alto desvio padrão, devido a este tratamento possuir uma maior heterogeneidade ambiental quanto à presença de gramíneas, 
com algumas parcelas bastante infestadas, mas não como uma vegetação dominante. A densidade de vegetação de 0 a 3 metros de altura mostrou médias intermediárias em relação aos outros tratamentos, porem com níveis de estratificação ainda baixos, mostrando um ambiente estruturalmente diferente do dos fragmentos.

Tabela 4 Tabela das médias para cada variável ambiental amostrada nos tratamentos, onde d.p. é o desvio padrão para cada média:

\begin{tabular}{|c|c|c|c|c|c|c|c|c|c|c|}
\hline Habitat & $\begin{array}{c}\text { Densidade } \\
\text { de }\end{array}$ & d.p & $\begin{array}{c}\text { Cobertura } \\
\text { de } \\
\text { Copas } \\
(\%)\end{array}$ & d.p & $\begin{array}{c}\text { Densidade } \\
\text { Vegetação } \\
0-3 \text { m } \\
(\%)\end{array}$ & d.p & $\begin{array}{l}\text { Área } \\
\text { basal } \\
\left(\mathbf{m}^{2} / \mathbf{h a ́}\right)\end{array}$ & d.p & $\begin{array}{c}\mathbf{H} \\
\text { dominante } \\
(\mathrm{m})\end{array}$ & d.p \\
\hline $\begin{array}{l}\text { Média } \\
\text { FRAG }\end{array}$ & 2387 & 8.20 & 80.28 & 2.21 & 61.33 & 21.05 & 2890 & 10.10 & 23.12 & 2.82 \\
\hline $\begin{array}{l}\text { Média } \\
\text { PAST }\end{array}$ & 85.23 & 5.15 & 0.56 & 0.96 & $12.44^{*}$ & 8.68 & 0.00 & 0.00 & 0.00 & 0.00 \\
\hline $\begin{array}{l}\text { Média } \\
\text { REST }\end{array}$ & 37.48 & 21.25 & 61.17 & 12.29 & 28.00 & 2.67 & 18.63 & 6.90 & 1457 & 0,91 \\
\hline
\end{tabular}

* No caso da pastagem a densidade do sub-bosque representa a densidade de vegetação arbustiva e herbáceas de grande porte.

As áreas em restauração se comportam como intermediárias quanto à estrutural vegetacional, pois segundo LOMOV et al., (2006), combinam elementos e estrutura de floresta nativa e pastagem.

Para verificar a possível correlação das variáveis de habitat estudadas com a comunidade de borboletas frugívoras, foi feita uma análise de correlação por regressão múltiplas do tipo stepwise, onde a variável dependente foi o numero de espécies e abundâncias das borboletas e as variáveis independentes foras as cinco variáveis ambientais estudadas (Tabela 5).

Para abundância de borboletas como variável dependente, a correlação entre as variáveis ambientais avaliadas neste estudo não foi significativa a $5 \%$ de probabilidade (Tabela 5). Para variável dependente número de espécies $(\mathrm{N})$, as variáveis ambientas que se correlacionaram significativamente a $5 \%\left(\mathrm{p}=0,028\right.$ e $\mathrm{f}_{(5,3)}=2,82 ; \mathrm{R}$ múltiplo $=0,51, \mathrm{R}^{2}=0,26$ e $\mathrm{R}^{2}$ ajustado $\left.=0,17\right)$, foram: a densidade de vegetação herbácea ( 0 $3 \mathrm{~m}$ ) (correlação negativa; $\mathrm{p}=0,003$ ) e densidade de cobertura de copas (correlação positiva; $\mathrm{p}=0,037)$ (tabela 5). 

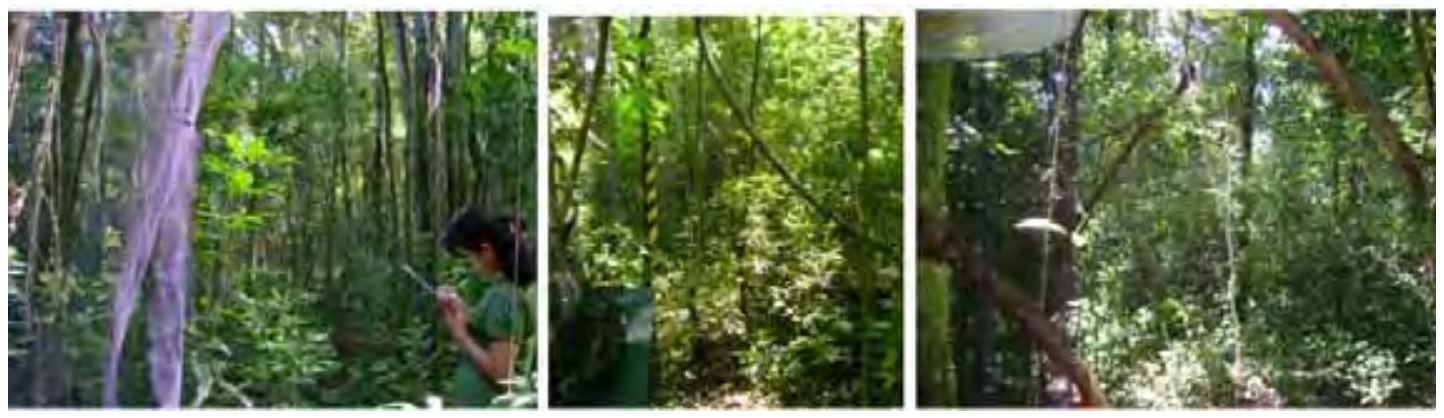

Figura 17 Fotos dos fragmentos de cada sítio (1, 2 e 3 consecutivamente) estudados.
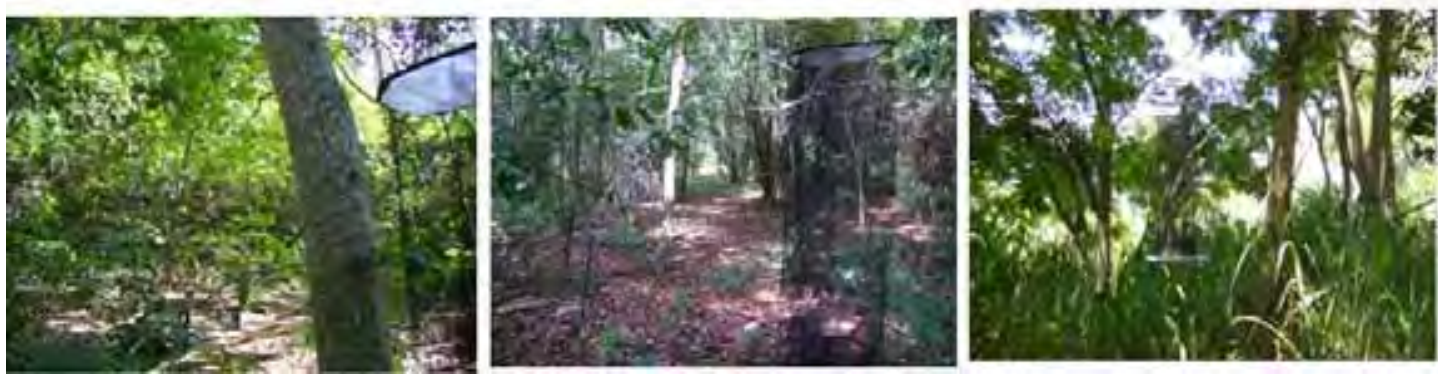

Figura 18 Fotos das áreas em processo de restauração de cada sítio $(1,2$ e 3 consecutivamente) estudados.
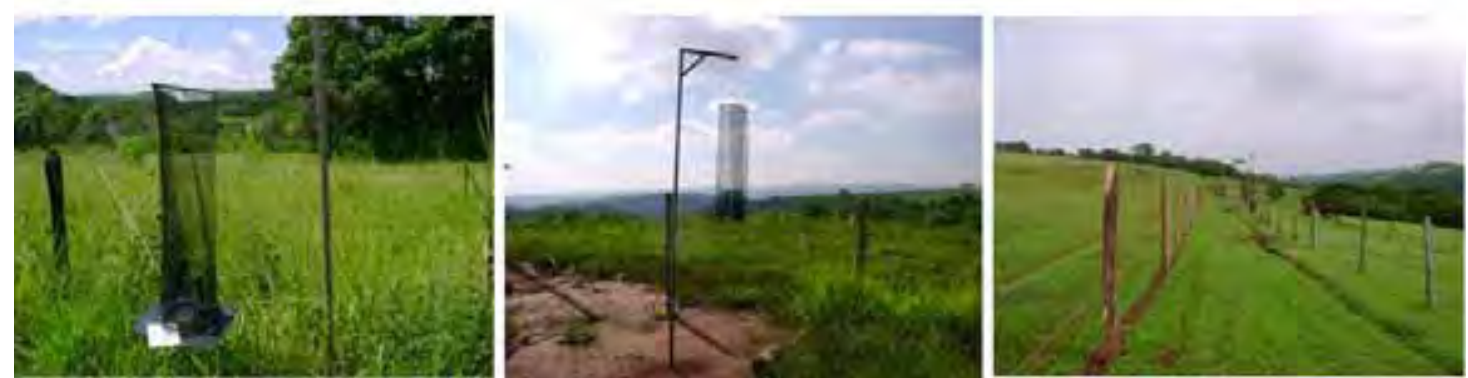

Figura 19 Fotos das pastagens de cada sítio (1, 2 e 3 consecutivamente) estudados.

Tabela 5 Coeficientes de correlação parcial (Cfcrp) das análises de regressão múltipla do tipo stepwise para a variável dependente $\mathrm{N}$ (número de espécies borboletas frugívoras).

\begin{tabular}{lcc}
\hline & \multicolumn{2}{c}{ Variável dependente } \\
Variável independente & Número de espécies (N) \\
& Cfcrp & p \\
\hline Dens. vegetaçấo $0-3 \mathrm{~m}(\%)$ & $(-) 0,4514$ & $\mathbf{0 , 0 0 3 0}$ \\
Ảrea basal $\left(\mathrm{m}^{3} / \mathrm{ha}\right)$ & $(-) 0,2211$ & 0,1646 \\
H domin.(m) & 0,1251 & 0,4355 \\
Dens.Herbáceas (\%) & 0,1333 & 0,4057 \\
Dens. Cob, Copa (\%) & 0,3254 & $\mathbf{0 , 0 3 7 8}$ \\
\hline
\end{tabular}


O resultado permite especular que as variáveis do ambiente que influenciaram na composição da comunidade de borboletas frugívoras para estes tratamentos avaliados indicam uma sensibilidade de borboletas frugívoras à intensidade de luz e oferta de recurso para indivíduos jovens.

Borboletas frugívoras têm sido usadas para estudos em ecossistemas perturbados, e revelaram ser sensíveis a distúrbios, permitindo que se façam avaliações de impactos ecológicos e de estratégias de conservação, como em sistemas agroflorestais (BOUYER et al., 2007).Alguns estudos têm demonstrado boas relações entre abundância e riqueza de espécies com a abundância e estrutura da vegetação (RAMOS, 2000 e HAMMER et al., 1997) e que a relação a nível de espécies são boas indicadoras de fragmentação da paisagem (UEHARA-PRADO et al., 2007), áreas perturbadas e não perturbadas (UEHARAPRADO et al., 2009). 


\section{CONCLUSÕES}

A composição e abundância de espécies de borboletas foi diferente para cada tratamento (fragmento, restauração e pasto) Embora o número de espécies e a abundância observados tenham sido maiores nas áreas em restauração, os fragmentos apresentaram maior riqueza esperada (para amostras com mesmo número de indivíduos) e maior diversidade (alfa de Fisher), seguidos pelas áreas em restauração e por último pelas pastagens. As áreas em processos de restauração apresentaram uma comunidade complexa,, pelo fato de combinar elementos da comunidade de borboletas dos fragmentos e das pastagens, sendo entretanto muito mais semelhantes aos fragmentos do que a essas últimas. As características estruturais do habitat (densidade de vegetação herbácea e cobertura de copas) se mostraram importantes para condicionar a comunidade de borboletas frugívoras.

As áreas em restauração podem ser consideradas como comunidades de transição entre pastagens e fragmentos, sendo importantes para conservação da biodiversidade local e na escala da paisagem. Embora a composição da comunidade de borboletas frugívoras das áreas de restauração tenha diferido entre os três sítios, a riqueza e diversidade dessas áreas foram comparáveis, indicando que restauração ecológica pode seguir diferentes trajetórias sucessionais diferentes. 
Algumas espécies de Nymphalideae demonstraram potenciais e podem ser recomendadas como indicadoras de processos de restauração. Callicore sorana foi características de áreas degradadas, sendo favorecida por habitas extremamente abertos, neste caso as pastagens. Representantes da subfamília Morphinae (Morphos elenor) podem ser considerados como indicadores de habitats mais bem estruturados e complexos (fragmentos). E espécies da subfamília Satyrinae (Yphthimoides sp; Taygetis laches;Paryphthimoides phronius; Paryphthimoides polti;) e Charaxinae (Memphis ryphea) e Biblidinae (Hamadryas februa) são características de habitats intermediários, como as áreas em restauração.

O estudo da guilda de borboletas frugívoras mostrou dados consistentes e satisfatórios para os objetivos do trabalho, merecendo mais pesquisas quanto a espécies indicadoras potenciais de qualidade de habitat e de reestruturação de comunidades em restauração.

Um estudo mais longo e com um número maior de repetições poderia fornecer um padrão de composição e distribuição das espécies que colonizam áreas em processo de restauração, visando estabelecer um protocolo para monitoramento de áreas em processo de restauração. 


\section{REFERÊNCIAS BIBLIOGRÁFICAS}

AB'SÁBER, A. N. Os domínios de natureza no Brasil: potencialidades paisagísticas. São Paulo: Ateliê Editorial, 2003. 159 p.

ACCASIO, G. M.; FREITAS, A. V. L.; URSO-GUIMARÃES, M. V. Invertebrados. In: RODRIGUES, R.; BONONI, V. L.R. (Orgs.). Diretrizes para a conservação e a restauração da biodiversidade no Estado deSão Paulo. São Paulo: Imprensa Oficial, 2008. Cap.6, p. 99-103.

ALMEIDA, A. F. Interdependência das florestas plantadas com a fauna silvestre. Série Técnica IPEF, Piracicaba, v. 10, n. 29, p. 36-44, nov. 1996.

BARLOW, J. et al. The value of primary, secondary and plantation forests for fruit-feeding butterflies in the Brazilian Amazon. Journal of Applied Ecology, v. 44, p. 1001-1012, 2007.

BORDONI, E.; OLIVEIRA, V. H. F.; MADEIRA, B. G. Variação temporal e efeito da precipitação e temperatura na diversidade de borboletas frugívoras (Lepidóptera: Nymphalidaes) em uma área de transição entre o cerrado e a floresta estacional decídua Caxambú -MG, 2007. In: CONGRESSO DE ECOLOGIA DO BRASIL, 8., 2007, Caxambu. Anais... Caxambu: 2007. 2p. 
BOUYER, J. et al. Identification of ecological indicators for monitoring ecosystem health in the trans-boundary W Regional park: a pilot study. Biological Conservation, v. I38, p. 73-88, 2007.

BRASIL. Ministério do Meio Ambiente. Avaliação e ações prioritárias para a conservação da biodiversidade da Mata Atlântica e Campos Sulinos. Brasília, DF, 2000. 40 p.

BROWN, K. S. Jr. Borboletas da Serra do Japi: diversidade, habitats, recursos alimentares e variação temporal. In: MORELLATO, L. P. C. (Org.). História natural da Serra do Japi: ecologia e preservação de uma área florestal no sudeste do Brasil. Campinas: Editora UNICAMP; FEPESP, 1992. p. 142- 186.

BROWN, K. S. Jr. Conservation of neotropical environments: Insects as indicators. In: COLLINS, N.M.; THOMAS, J.A.(org). The conservation of insects and their habitats. Academic Press, London. P. 349-404. 1991.

BROWN, K. S. Jr. Conservation of threatened species of Brazilian butterflies In: AE, S. A. et al. (Ed.). Decline and conservation of butterflies in Japan Yadoriga (special issue). Osaka: Lepidopterist Society of Japan, 1996. p. 45-62.

BROWN, K. S. Jr. Diversity, disturbance, and sustainable use of Neotropical forests: insects as indicators for conservation monitoring. Journal of Insect Conservation, v. 1, p. 25-42, 1997.

BROWN, K. S. Jr. Maximizing daily butterfly counts. Journal of the Lepidopterists' Society, v. 26, p. 183-196, 1972.

BROWN, K. S. Jr.; FREITAS, A. V. L. Atlantic forest butterflies: indicators for landscape conservation. Biotropica, v. 32, p. 934-956, 2000.

CAES, B. R. M. Mastofauna terrestre associada a áreas em processo de restauração na fazenda experimental Edgárdia, Botucatu - SP. 2009. 69 p. Dissertação (Mestrado em Engenharia Florestal)- Faculdade de Ciências Agronômicas, Universidade Estadual Paulista, Botucatu, 2009.

CASSOLA, H. Aspectos da estrutura fitossociológica e silvigenética em fragmentos de floresta estacional semidecídua com diferentes histórias de perturbação em Botucatu, SP. 2008. 85 p. Dissertação (Mestrado em Recursos Florestais/ Conservação de Ecossistemas 
Florestais)- Escola Superior de Agricultura Luiz de Queiroz, Universidade de São Paulo, Piracicaba, 2008.

CONSERVAÇÃO INTERNACIONAL BRASIL. Mapa hotspots. Belo Horizonte, 2003. Disponível em: <http://www.conservation.org.br/como/index.php?id=8>. Acesso em: 21 ago. 2009.

D'ABRERA, B. Butterflies of the neotropical region: part III: Brassolidae, Acraeidae \& Nymphalidae (partim).Victoria: Hill House, 1987a. 53 p.

D'ABRERA, B. Butterflies of the neotropical region: part IV: Nymphalidae (partim). Victoria: Hill House, 1987b. 147 p.

D'ABRERA, B. Butterflies of the neotropical region: part V: Nymphalidae (conc.) \& Satyridae. Victoria: Hill House, 1988.143 p.

DAILY, G. C.; EHRLICH, P. R. Preservation of biodiversity in small rainforest patches: rapid evaluation using butterfly trapping. Biodiversity and Conservation, v. 4, p. 35-55, 1995.

DEVRIES, P. J. Stratification of fruit-feeding nymphalid butterflies in a Costa Rican rainforest. Journal of Research on the Lepidoptera, v. 26, p. 98-108, 1988.

DEVRIES, P. J. The butterflies of Costa Rica and their natural history: Papilionidae, Pieridae, and Nymphalidae. Princeton: Princeton University Press, 1987. 327 p.

DEVRIES, P. J.; MURRAY, D.; LANDE, R. Species diversity in vertical, horizontal, and temporal dimensions of a fruit-feeding butterfly community in an Ecuadorian rainforest. Biological Journal of the Linnean Society, London, v. 62, p. 343-364, 1997.

DEVRIES, P. J.; WALLA, T. R. Species diversity and community structure in neotropical fruit-feeding butterflies. Biological Journal of the Linnean Society, v. 74, p. 1-15, 2001.

ENGEL, V. L.; PARROTTA, J. A. An evaluation of direct seeding for restoration of degraded lands in central São Paulo state, Brazil. Forest Ecology and Management, v. 152, p. 169$181,2001$. 
ENGEL, V. L.; PARROTTA, J. A. Definindo a restauração ecológica: tendências e perspectivas mundiais. In: KAGEYAMA, P. Y. et al. (Org.) Restauração ecológica de ecossistemas naturais. Botucatu: FEPAF, 2003. p. 1-26.

ENGEL, V. L.; PARROTTA, J. A. Sistemas alternativos de plantio para a restauração de ecossistemas florestais da Mata Atlântica em Botucatu, SP. Agroecologia Hoje, v. 1, n. 5, p. 10-11, 2000.

FAHRIG, L. Effects of habitat fragmentation on biodiversity. Annual Review Ecology, Evolution and Systematics, v. 34, p. 487-515, 2003.

FONSECA, R. C. B.; RODRIGUES, R. R. Análise estrutural e aspectos do mosaico sucessional de uma floresta semidecídua em Botucatu, SP. Scientia Forestalis, n. 57, p. 27 43, 2000 .

FREITAS, A. V. L.; BROWN, K. S. Jr. Phylogeny of the Nymphalidae (Lepidoptera). Systematic Biology.v. 53, p.363-383, 2004.

FREITAS, A. V. L.; FRANCINI, R. B.; BROWN, K. S. Jr. Insetos como indicadores ambientais. In: CULLEN JUNIOR, L. et al., Métodos de estudos em biologia da conservação e manejo da vida silvestre. Curitiba: Editora da UFPR; Fundação O Boticário de Proteção à Natureza, 2003. cap. 5, p. 125-151.

FREITAS, A. V. L.; I. R. LEAL; M. UEHARA-PRADO \& L. IANNUZZI. Insetos como indicadores de conservação da paisagem. In: C. F. Rocha; H. Bergalo; M. Van Sluys \& M. A. Alves (orgs.). Biologia da Conservação. Rio de Janeiro, Editora da UERJ. p. 201-225, 2006.

GARCIA, I. P. et al. Ecological interaction between Atta sexdens (Hymenoptera: Formicidae) and the vegetation of a mesophyll semideciduous forest fragment in Botucatu, SP, Brazil.

Sociobiology, v. 42, n. 2, p. 265-283, 2003.

GONÇALVES, J. L. M.; NOGUEIRA JUNIOR, L. R.; DUCATTI, F. Recuperação de solos degradados. In: KAGEYAMA, P. Y. et al. (Org.) Restauração ecológica de ecossistemas naturais. Botucatu: FEPAF, 2003. p. 112-163.

GONÇALVES, R. M. G. et al. Aplicação de modelo de revegetação em áreas degradadas, visando à restauração ecológica da microbacia do córrego da fazenda Itaqui, no município de Santa Gertrudes, SP. Revista do Instituto Florestal, São Paulo, v. 17, n. 1, p. 73-95, jun. 2005. 
HAMER, K. C. et al. Ecological and biogeographical effects of forest disturbance on tropical butterflies of Sumba, Indonesia. Journal of Biogeography, v. 24, p. 67-75, 1997.

HAMMER, O.; HARPER, D. A. T.; RYAN, P. D. PAST: paleontological statistics software package for education and data analysis. Palaentologia Electronica, v. 4, 2001. Disponível em: <http://palaeo-electronica.org/2001_1/past/issue1_01.htm>. Acesso em: 13 ago. 2009.

INSTITUTO BRASILEIRO DE GEOGRAFIA E ESTATÍSTICA. Manual técnico da vegetação brasileira. Rio de Janeiro, 1992. 92p.

INSTITUTO BRASILEIRO DE GEOGRAFIA E ESTATÍSTICA. O mapa de biomas e vegetações do Brasil, 2003. Disponível em:

<http://ftp.ibge.gov.br/DiretórioFTP/Cartas_e_Mapas/Mapas_Murais/>. Acesso em: 20 out. 2009.

JORGE, L. A. B.; SARTORI, M. S. Uso do solo e análise temporal da ocorrência de vegetação natural na Fazenda Experimental Edgárdia, em Botucatu-SP. Revista Árvore, Viçosa, v. 26, n. 5, p. 585-592, 2002.

KAGEYAMA, P. Y.; REIS, A.; CARPANEZZI, A. A. Potencialidades e restrições da regeneração artificial na recuperação de áreas degradadas. In: SIMPÓSIO NACIONAL SOBRE RECUPERAÇÃO DE ÁREAS DEGRADADAS, 1., 1992, Curitiba. Anais... Curitiba: UFPR; FUPEF, 1992. p. 1-16.

KREMEN, C. et al. Terrestrial arthropod assemblages: Their use in conservation. Conservation Biology, v. 7, n. 4, p. 796-808, Dec. 1993.

LAURANCE, W. F.; USECHE, D. C. Environmental synergisms and extinctions of tropical species. Conservation Biology. V. 23, p. 1427-1437, 2009.

LAURANCE, W.F., ALBERNAZ, A., AND DA COSTA, C. Is deforestation accelerating in the Brazilian Amazon? Environment Conservation. v.28, p. 305-311. 2001.

LEITÃO-LIMA, P. S. Levantamento da entomofauna em sítios florestais em recuperação e em um fragmento de floresta natural em Botucatu, SP. 2002. 106 f. Dissertação (Mestrado em Agronomia/Proteção de Plantas)-Faculdade de Ciências Agronômicas, Universidade Estadual Paulista, Botucatu, 2002. 
LEWINSOHN, T. M.; FREITAS, A.V.; PRADO, P. I. Conservação de invertebrados terrestres e seus habitats no Brasil. Megadiversidade, Campinas, SP, v. 1. n. 1, p. 1-2, 2005.

LINDERNMAYER, D. B. Future directions for biodiversity conservation in managed forests: indicator species, impact studies and monitoring programs. Forest Ecology and Management. V. 115, p.277-287. 1999.

LOMOV, B. et al. Are butterflies and moths useful indicators for restoration monitoring?: a pilot study in Sydney's Cumberland Plain Woodland. Ecological Management \& Restoration, Austrália, v. 7, n. 3, p.204-210, Dec. 2006.

LOUZADA, J. N. C.; SOUZA, O. F. F.; BERG, E. V. D. Ecologia e manejo de fragmentos florestais. Lavras: UFLA; FAEPE, 2001. 41 p. Módulo do Curso de Pós-Graduação Lato Sensu.

MAGURRAN, A. E. Measuring biological diversity. Oxford: Blackwell Science, 2004. 256 p.

MAJER, J. D. Animals in the restoration process: progressing the trends. Restoration Ecology, Western Austrália,, v. 17, n. 3, p. 315-319, 2009.

MAJER, J. D. Fauna studies and land reclamation technology: a review of the history and need for such studies. In: MAJER, J. D. (Coord.). Animals in primary succession the role of fauna in reclaimed lands. Londres: Cambridge University Press, 33 p.1989.

MANTOVANI, W. Delimitação do bioma Mata Atlântica: implicações legais e conservacionistas. In: CLAUDINO-SALES, V. (Org.). Ecossistemas brasileiros: manejo e conservação. Fortaleza: Expressão, 2003. p. 287-295.

MARTINS, D. Classificação climática Botucatu-SP. Botucatu: UNESP, Faculdade de Ciências Agronômicas, Departamento de Ciências Ambientais, 2 p. 2009.

MARTINS, F. R.; SANTOS, F. A. M. Técnicas usuais de estimativa da biodiversidade.

Revista Holos, Campinas, SP, p. 236-267, 2009. Edição especial. Disponível em: $<$ http://famsantos.vilabol.uol.com.br/holos.htm>. Acesso em: 2 out. 2009.

METZGER, J. P. Estrutura da paisagem e fragmentação: análise bibliográfica. Anais da Academia Brasileira de Ciências, v. 71, n. 3, p. 445-463, 1999. 
MITTERMEIER, R. A. et al. (Eds.). Hotspots revised: earth's biologically richest and most endangered terristrial ecoregions. Washinton, DC: Cemex, 2004. 390 p.

MUELLER-DUMBOIS, D.; ELLENBERG, H. Aims and methods of vegetation ecology. New York: John Wiley, 1974. 547 p.

MYERS, N. et al. Biodiversity hotspots for conservation priorities. Nature, v. 403, p. 853$845,2000$.

MYERS, N. Tropical forests and their species: going, going...? In: WILSON, E. O. (Ed.). Biodiversity. Washington, DC: National Academic, p. 28-35. 1988.

NEW, T. R. et al. Butterfly conservation management. Annual Review of Entomology, v. 40, p. 57-83, 1995.

NEWTON, A. C. Forest ecology and conservation. Oxford: Oxford University Press, 2007. $454 \mathrm{p}$.

NOGUEIRA JUNIOR, L. Caracterização de solos degradados pela atividade Agrícola e alterações biológicas após reflorestamentos com diferentes associações de espécies da mata atlântica. 2000. 49 p. Dissertação (Mestrado em Recursos Florestais)-Escola Superior de Agricultura Luiz de Queiroz, Universidade de São Paulo, Piracicaba, 2000.

ORTEGA, V. R.; ENGEL, V. L. Conservação da biodiversidade de remanescentes de mata atlântica na região de Botucatu, SP. Revista do Instituto Florestal, São Paulo, v. 4, p. 839852, 1992. Número único.

PARROTA, J. A; TURNBULL, J. W.; JONES, N. Catalyzing native forest regeneration on degraded tropical lands. Forest Ecology and Management, v. 99, n. 1/2, p. 1-7, 1997.

PINHEIRO, C. E. G.; ORTIZ, J. V. C. Communities of fruit-feeding butterflies along a vegetation gradient in central Brazil. Journal Biogeography. v. 19, p. 505-511, 1992.

POYRY,J.; LINDGREN, S.; SALMINEN, J.; KUUSSAARI, M. Responses of butterfly and month species to restored cattle grazing in semi-natural grasslands. Biological Conservation. v. 122. p.465-478, 2005. 
PRIMACK, R.B.; RODRIGUES, E. Biologia da conservação. Londrina, PR. 338p. 2001.

RAMOS, F. A. Nynphalidae butterfly communities in an Amazonian forest fragment. Journal of Research on the Lepidoptera, Brasília, DF, v. 35, p. 29-41, 2000.

REIS, A.; KAGEYAMA, P. Y. Restauração de áreas degradadas utilizando as interações planta-animal. In: KAGEYAMA, P. Y. et al. (Org.). Restauração ecológica de ecossistemas naturais. Botucatu: FEPAF, 2003. p. 91-110.

RESERVA da biosfera da Mata Atlântica. São Paulo, 2009. Disponível em: $<$ http://www.rbma.org.br>. Acesso em: 21 ago. 2009.

RODRIGUES, R. R.; BRANCALION, P. H. S.; ISERNHAGEN, I. Pacto pela restauração da mata atlântica: referencial dos conceitos e ações de restauração florestal. São Paulo: LERF; ESALQ, Instituto BioAtlântica, 2009. 259 p.

RODRIGUES, R. R.; GANDOLFI, S. Conceitos, tendências e ações para recuperação de florestas ciliares. In: RODRIGUES, R. R.,; LEITÃO-FILHO, H. de F. (Eds.). Matas ciliares: conservação e recuperação. São Paulo: EdUSP, 2004. p. 235-247.

ROSA, G. A. B. Frugivoria e dispersão de sementes por aves em uma área de reflorestamento misto em Botucatu, SP. 2003. 69 p. Dissertação (Mestrado em Ecologia)Universidade Estadual de Campinas, Campinas, 2003.

RUIZ-JAÉN, M. C.; AIDE, M. T. Restoration succes: how is it being measured? Restoration Ecology, v. 13, n. 3, p. 569-577, 2005.

SAWCHIK, J. et al. Metapopulation dynamics of the bog fritillary butterfly: modelling the effect of habitat fragmentation. Acta Oecologica, p. 287-296, 2002.

SAWCHIK, J.; DUFRÊNE, M.; LEBRUN, P. Distribution patterns and indicator species of butterfly assemblages of wet meadows in southern Belgium. Belgium Journal Zool. V. 135, n. 1, p. 43-52. 2005.

SHUEY, J. A. An optimizing portable bait trap for quantitative sampling of butterflies. Tropical Lepidóptera, v. 8, n. 1, p. 1-4, 1997. 
SOCIETY FOR ECOLOGICAL RESTORATION INTERNATIONAL. Principios de SER International sobre la restauración ecológica. Tucson, 2004. 15 p. Disponível em: $<$ http://www.ser.org/content/spanishprimer.asp>. Acesso em: 20/12/2009.

SOUZA, P. A. Comportamento de 12 espécies arbóreas em recuperação da área degradada pela extração de areia. 2000. 92 p. Dissertação (Mestrado em Engenharia Florestal)-Universidade Federal de Lavras, Lavras, MG, 2000.

SUDING, K. N.; GROSSK, L. The dynamic of ecological systems: multiple states and restoration trajectories. In: FALK, D. A.; PALMER, M. A.; ZEDLER, J. B. (Eds.). Foundation of restoration ecology. Washington, DC: Island, 2006. p. 190-209.

THOMAS, J.A. Monitoring change in the abundante and distribution os insects using butterflies and other indicador groups. Philosophical Transactions of the royal society B. v. 360, p. 339-357. 2005.

UEHARA-PRADA, M. et al. Selecting terrestrial arthropds as indicators of small-scale disturbance: A primary approach im Brazilian Atlantic Forest. Biological Conservation, v. 142, n. 6, p. 1220-1228, 2009.

UEHARA-PRADO, M. et al. Borboletas frugívoras (Lepidóptera: Nymphalidae) como indicadoras de fragmentação florestal no Planalto Atlântico Paulista. In: CONGRESSO DE ECOLOGIA DO BRASIL, 6., Fortaleza. Anais... Fortaleza: Editora da Universidade Federal do Ceará, 2003. p.297-299.

UEHARA-PRADO, M., Efeitos da fragmentação florestal na guilda de borboletas frugívoras do Planalto Atlântico Paulista. 2003. 144 f. Dissertação (Mestrado em Ecologia)Instituto de Biologia, Universidade Estadual de Campinas, Campinas, 2003.

UEHARA-PRADO, M.; BROWN, K. S. Jr.; FREITAS, A. V. L. Biological traits of frugivorous butterflies in a fragmented and a continuous landscape in the South Brazilian Atlantic Forest. Journal of the Lepidopterists' Society, v. 59, p. 96-106, 2005.

UEHARA-PRADO, M.; BROWN, K. S. Jr.; FREITAS, A. V. L. Species richness, composition and abundance of fruit-feeding butterflies in the Brazilian Atlantic Forest: comparison between a fragmented and a continuous landscape Global Ecology and Biogeography, v. 16, p. 43-54, 2007. 
UEHARA-PRADO, M.; FREITAS, A. L.; FRANCINI, R. B. Guias das borboletas frugívoras da reserva estadual do Morro Grande e região de Caucaia do alto, Cotia (SP). Biota Neotropica, v. 4, n. 1, p. 1-9, 2004. Disponível em:

$<\mathrm{http}$ ://www.biotaneotropica.org.br/v4n1/pt/abstract?inventory+BN00504012004>. Acesso em: 5 fev. 2006.

WHITE, P. S.; JENTSCH, A. Disturbance, succession, and community assembly in terrestrial plant communities. In: TEMPERTON, V. M. et al (Org.). Assembly rules and restoration ecology: bridging the gap between theory and practice. Washington, DC: Island, 2004. p. 342366. 